\title{
Experimental Drugs for Chemotherapy- and Cancer-Related Anemia
}

\author{
Clelia Madeddu' \\ Manuela Neri $\mathbb{D}^{2}$ \\ Elisabetta Sanna ${ }^{2}$ \\ Sara Oppi ${ }^{3}$ \\ Antonio Macciò ${ }^{2}$ \\ 'Department of Medical Sciences and \\ Public Health, University of Cagliari, \\ Cagliari, Italy; ${ }^{2}$ Department of \\ Gynecologic Oncology, A. Businco \\ Hospital, ARNAS G. Brotzu, Cagliari, \\ Italy; ${ }^{3}$ Hematology and Transplant \\ Center, A. Businco Hospital, ARNAS \\ G. Brotzu, Cagliari, Italy
}

\begin{abstract}
Anemia in cancer patients is a relevant condition complicating the course of the neoplastic disease. Overall, we distinguish the anemia which arises under chemotherapy as pure adverse event of the toxic effects of the drugs used, and the anemia induced by the tumour-associated inflammation, oxidative stress, and systemic metabolic changes, which can be worsened by the concomitant anticancer treatments. This more properly cancerrelated anemia depends on several overlapping mechanism, including impaired erythropoiesis and functional iron deficiency, which make its treatment more difficult. Standard therapies approved and recommended for cancer anemia, as erythropoiesis-stimulating agents and intravenous iron administration, are limited to the treatment of chemotherapyinduced anemia, preferably in patients with advanced disease, in view of the still unclear effect of erythropoiesis-stimulating agents on tumour progression and survival. Outside the use of chemotherapy, there are no recommendations for the treatment of cancer-related anemia. For a more complete approach, it is fundamentally a careful evaluation of the type of anemia and iron homeostasis, markers of inflammation and changes in energy metabolism. In this way, anemia management in cancer patient would permit a tailored approach that could give major benefits. Experimental drugs targeting hepcidin and activin II receptor pathways are raising great expectations, and future clinical trials will confirm their role as remedies for cancer-related anemia. Recent evidence on the effect of integrated managements, including nutritional support, antioxidants and anti-inflammatory substances, for the treatment of cancer anemia are emerging. In this review article, we show standard, innovative, and experimental treatment used as remedy for anemia in cancer patients.
\end{abstract}

Keywords: hemoglobin, cancer-related anemia, chemotherapy-induced anemia, energy metabolism, inflammation, iron homeostasis, erythropoietin, interleukin-6

\section{Introduction}

Anemia in patients with cancer is still a relevant problem affecting both general health and quality of life. According to the definition of the World Health Organization, anemia occurs when hemoglobin (Hb) levels drop below $12 \mathrm{~g} / \mathrm{dL}$ for women and $13 \mathrm{~g} / \mathrm{dL}$ for men, ${ }^{1}$ and severity ranges from mild to severe or life threatening. It can be classified into two important forms: (1) anemia occurring as an adverse event consequent to the toxic effect of anticancer treatment ("chemotherapy-induced anemia") and (2) anemia occurring as a manifestation of the disease itself, more aptly called "cancer-related anemia," resulting from systemic processes and immune system activation in cancer. ${ }^{2}$ The incidence of anemia in patients with cancer depends on the tumor type and stage. Obviously, the incidence is particularly high in hematologic malignancies, affecting more than half of
Correspondence: Antonio Macciò A. Businco Hospital, ARNAS G. Brotzu, via Jenner, Cagliari, 09100, Italy Tel +390706754228

Email antoniomaccio56@gmail.com 
patients at diagnosis; in these cases, anemia is caused by direct damage of the bone marrow and erythroid stem cells. ${ }^{3}$ Among solid tumors, the most frequently associated with anemia are lung, gastrointestinal, and ovarian cancers. ${ }^{3,4}$ Observational studies of large cohorts have reported low $\mathrm{Hb}$ levels in $20-30 \%$ of patients with cancer before starting any type of treatment and in $60-70 \%$ during anticancer therapy. ${ }^{3,5}$ Indeed, chemotherapy can both induce new cases of anemia and unmask anemia induced by the tumor, explaining this substantial increase in rates. In patients not undergoing chemotherapy, the prevalence and severity of cancer-related anemia is correlated with the stage of disease, appearing in $60-80 \%$ of patients with advanced disease. ${ }^{6}$ Considering the different mechanisms underlying anemia in patients with cancer, it is a nearly constant issue during disease progression.

Anemia has several deleterious effects in patients with cancer. The association between anemia and decreased survival in cancer is clearly established. Several observational studies have reported a negative impact of anemia on disease progression, response to chemo-/radiotherapy, survival, and risk of death, even for anemia occurring at an early cancer stage. ${ }^{7-16}$ Although anemia may be a consequence of more aggressive forms of cancer, which have worse outcomes, the additional mechanisms unrelated to the tumor may affect prognosis in patients with anemia. For example, anemia could increase hypoxia in the tumor microenvironment, a condition that is associated with resistance to radiotherapy and chemotherapy, tumor growth, tissue invasion, metastasis, poor outcomes. ${ }^{17}$ The anemic state, in proportion to its severity, leads to a set of symptoms, such as dyspnea, fatigue, dizziness, anorexia, lack of concentration, and depressed mood, and these symptoms compromise performance, daily functionality, and quality of life (QoL) ${ }^{18-20}$ As an additional consequence, adherence to anticancer treatments can be compromised by the reduced performance status due to anemia. Collectively, these factors make anemia a clinically relevant condition in patients with cancer, emphasizing the importance of investigations and management. In the present review, we describe the types of anemia in patients with cancer, their understanding mechanisms, and therapeutic strategies, including conventional treatments as well as novel and experimental approaches targeting iron metabolism, erythropoiesis, nutrient deficiencies, and inflammation. Literature search was performed by PUBMED using the following key words cancer-related anemia, chemotherapy-related anemia, iron AND cancer, Erythropoiesis AND cancer, Erythropoietin AND cancer, epoetin AND cancer, hepcidin AND cancer, functional-iron deficiency AND cancer, hemoglobin AND cancer, blood transfusion AND cancer, anemia AND treatment AND cancer. As for treatment we included "Clinical Trial" [Publication Type] OR "Randomized Controlled Trial" [Publication Type] OR "Clinical Trial, Phase III" [Publication Type] OR "Clinical Trial, Phase IV" [Publication Type] OR "MetaAnalysis" [Publication Type] OR "Practice Guideline" [Publication Type].

\section{Types of Anemia in Patients with Cancer}

Anemia in patients with cancer can have various, nonmutually exclusive underlying causes. As in all forms of anemia, the etiopathogenetic mechanisms underlying low hemoglobin levels in patients with neoplasms include defective red blood cell production (impaired erythropoiesis) and increased destruction (hemolysis) or blood loss. ${ }^{21}$ These mechanisms can be induced directly by cancer, as observed in cases of tumor infiltration of the bone marrow, neoplasms leading to bleeding, or chronic inflammationrelated cancers, or can be induced by cancer treatments. In the latter case, anemia related to chemotherapy is the most representative form of drug-induced anemia. Notably, anticancer treatments have different associations with anemia depending on the setting. Pure chemotherapy-induced anemia occurs as an adverse event during anticancer treatments in the adjuvant setting; thus, it appears in patients who were not previously anemic and are in good general health. When chemotherapy is used as the principal treatment in neoadjuvant setting or for advanced or inoperable malignancies, a systemic disease induced by cancer is present, and chemotherapy can unmask latent anemia or aggravate pre-existing anemia. Thus, in patients with advanced cancer, the effects of anticancer treatments on erythropoiesis may largely overlap with cancer-related chronic inflammation and subsequent cancer-related anemia.

It is important to consider the type of anemia because treatment responses may differ, particularly since cancerrelated anemia is related to a more complex set of pathogenetic mechanisms linked to the state of chronic inflammation (Figure 1). These mechanisms must be understood to improve the management of patients with cancer-related anemia. 


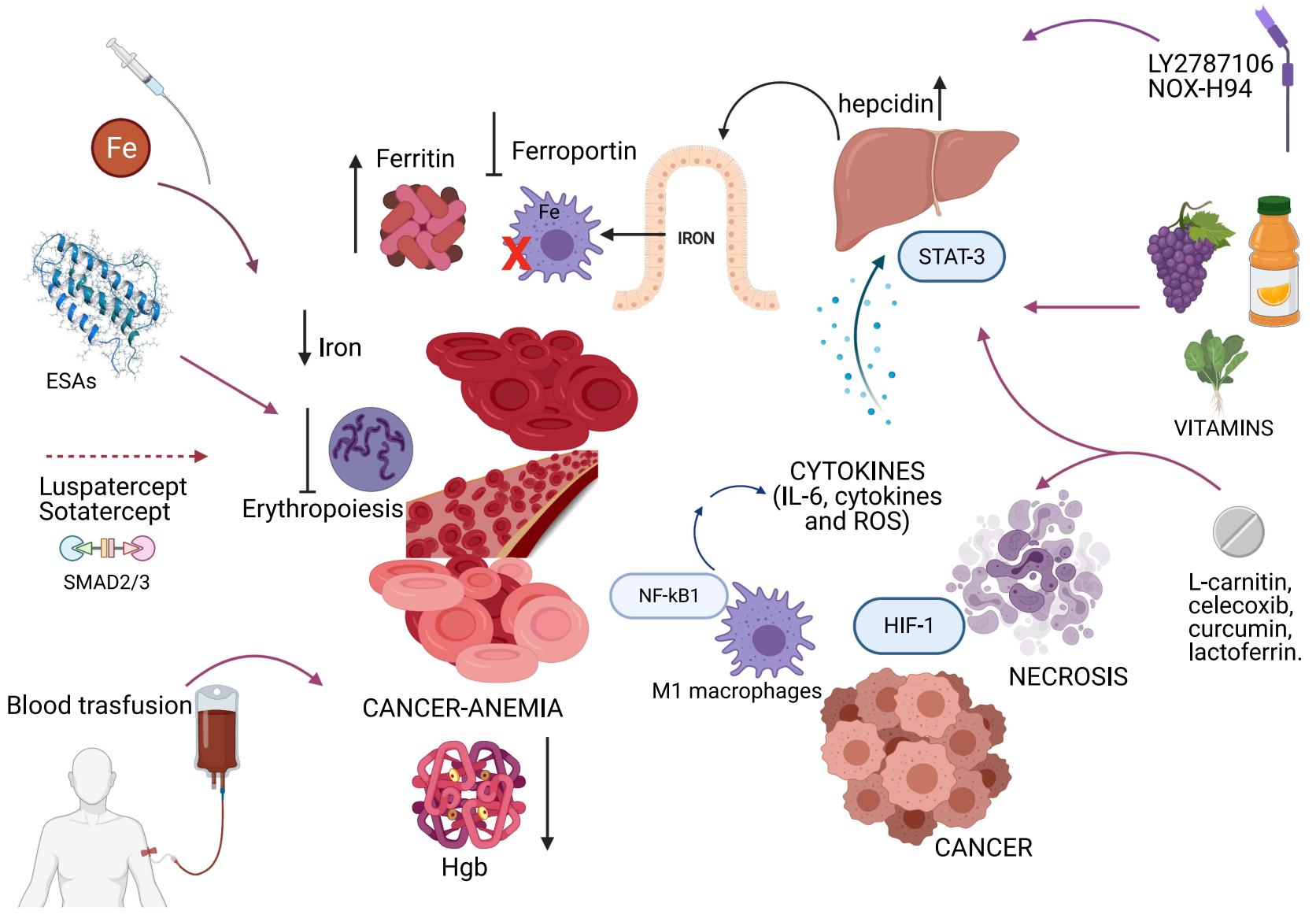

Figure I Pathogenetic mechanisms of cancer-related anemia and main related targeted approaches. The pathogenesis of cancer-related anemia involves multiple mechanisms induced by chronic inflammation associated to cancer and leading to functional iron deficiency and impaired erythropoiesis. Then, a multitargeted approach including conventional treatment such as ESAs, blood transfusion, iron therapy, as well as drugs targeting the inflammatory pathway, modulators of the iron metabolism, hepcidin antagonists, novel regulators of erythropoiesis and nutritional support should be considered. Figure was created in BioRender.com.

Abbreviations: ESAs, erythropoiesis stimulating agents; Hgb, haemoglobin; HIF, hypoxia inducible factor; NF- $\mathrm{KB}$, nuclear factor kappa-light-chain-enhancer of activated B cells; IL, Interleukin; ROS, reactive oxygen species; STAT-3, signal transducer and activator of transcription 3.

\section{Cancer-Related Anemia}

Clinically, cancer-related anemia is usually normochromic and normocytic, with a low reticulocyte count. ${ }^{22,23}$ Moreover, it is characterized in most most patients by low levels of EPO. ${ }^{24}$ Iron blood concentrations can be within normal values, despite an iron deficiency in $30-60 \%$ of patients with cancer. ${ }^{25}$ Usually, the total iron binding capacity is reduced, and ferritin blood values are elevated. ${ }^{26}$ As with various chronic diseases, cancer-related anemia is associated with chronic inflammation. Even if tumor cells themselves produce cytokines, cancer at an advanced stage and tissue necrosis induce the activation of immune cells (mainly macrophages) and the subsequent secretion of proinflammatory cytokines, such as interleukins (IL-6, IL-1, etc.), tumor necrosis factor alpha (TNF- $\alpha$ ), interferon gamma (IFN- $\gamma$ ) and amount of various chemokines. ${ }^{22}$ Increases in systemic inflammation finally lead to anemia via several overlapping mechanisms: a negative impact on erythroid precursors in the bone marrow with inadequate erythropoiesis, reduced production of erythropoietin (EPO), shortened red blood cell survival, and impaired iron metabolism in the reticuloendothelial system. ${ }^{2,22,27,28}$ Mainly, the negative effect on erythropoiesis is subsequent to iron restriction, a direct inhibitory effect on erythroid precursors, and a possible reduction in cytokine-induced EPO synthesis. ${ }^{23,28}$ Furthermore, some cytokines can indirectly reduce the expression of hypoxia-inducible factor 1 (HIF1), ${ }^{23}$ a transcription factor induced by hypoxia that stimulates EPO synthesis in the kidney. ${ }^{29}$ As clinical evidence for inadequate erythropoiesis, in cases of cancer-related anemia, responses to EPO treatment may be insufficient. ${ }^{24}$ The shortened erythrocyte survival can be attributed to the activation of macrophages by cytokines, which may increase red blood cell destruction. Moreover, 
increased erythrocyte fragility could follow increased oxidative stress $^{30}$ in patients with advanced cancer because of increased production of reactive oxygen species (ROS) under chronic inflammation. ${ }^{31,32}$ With respect to impaired iron metabolism, IL-6 and hepcidin have central roles. IL-6, produced both by cancer cells and M1 polarized macrophages, is a potent stimulator of hepatic hepcidin synthesis and hepcidin, in turn, is a modulator of iron metabolism by acting as an inhibitor of ferroportin, which allows trans-membrane iron transport. $^{33}$ Increased hepcidin levels limit the intestinal absorption or iron and prevent iron release from macrophages and reticuloendothelial cells. ${ }^{33}$ This creates a "functional" iron deficiency (FID), even if iron stores are appropriate. As proof of the link between inflammation, iron metabolism, and anemia, patients with solid tumors at different sites and stages show an inverse correlation between hemoglobin levels and IL-6, hepcidin, inflammatory markers (fibrinogen, C-reactive protein, and ferritin), and ROS, and IL-6 is an independent predictor of the hemoglobin concentration. ${ }^{31}$ In the same study, hemoglobin levels were positively correlated with leptin, cholesterol, albumin, and body mass index, which are generally related to nutritional status. Indeed, cancer-related anemia in the advanced stage of disease can be affected by the nutritional status of patients due to reduced iron and vitamin intake. In fact, cancer-related anemia is frequently associated with weight loss, anorexia, and cachexia. ${ }^{2,34}$

Obviously, in patients with systemic neoplastic disease, the initiation of anticancer therapies can worsen or unmask the state of cancer-related anemia, and the two mechanisms underlying anemia (ie, the mechanisms linked to chronic inflammation and linked to chemotherapy) overlap. Conversely, if chemotherapy is effective and induces a regression of tumor cells, levels of inflammation should be reduced, thereby attenuating cancer-related anemia. From this perspective, effective chemotherapy, with adequate nutritional and symptomatic support, is curative of the systemic manifestations of cancer and could effectively resolve cancer-related anemia. Clinical studies are required to investigate trends in anemia according to the response to chemotherapy.

\section{Factors Involved in Chemotherapy-Induced Anemia}

Chemotherapy-induced anemia is hypoproliferative due to the toxic effect of anticancer treatments on bone marrow or to a nephrotoxic effect, influencing EPO production (Figure 2). The severity of chemotherapy-induced anemia is conventionally defined by the Common Terminology
Criteria for Adverse Events (CTCAE) proposed by the National Cancer Institute (NCI), which describes five grades of severity for each adverse event caused by cancer therapies. $^{35}$ According to this system, chemotherapyinduced anemia is classified as mild (grade 1 toxicity) for hemoglobin levels below the normal range to $10 \mathrm{~g}$ / $\mathrm{dL}$; moderate (grade 2 toxicity) for hemoglobin levels between 8.0 and $10.0 \mathrm{~g} / \mathrm{dL}$; severe (grade 3 toxicity) for hemoglobin levels between 6.5 and $7.9 \mathrm{~g} / \mathrm{dL}$; lifethreatening (grade 4 toxicity) when it is below $6.5 \mathrm{~g} / \mathrm{dL}$; and deadly (grade 5 toxicity). The incidence and severity of chemotherapy-induced anemia of course depend on the type of drug, dose, intensity, and number of cycles. In a multicenter study of more than 2800 patients with solid tumors, the incidence of anemia rose from $17 \%$ before the first chemotherapy cycle to $35 \%$ at the sixth cycle; patients with ovarian and lung cancer showed the highest prevalence of chemotherapy-induced anemia. ${ }^{36}$ Grade 3-4 anemia was found during chemotherapy in $5.5 \%$ of cases overall in a series of Chinese patients with solid tumors who were not anemic before the start of treatment. ${ }^{37}$ Factors associated with an increased incidence and severity of anemia are advanced age and concomitant leukopenia and thrombocytopenia. ${ }^{37}$ All anticancer treatments may result in anemia; however, the condition is often induced by platinum-based regimens. ${ }^{37,38}$ Indeed, beyond the direct toxic effect on erythropoiesis, platinum-based chemotherapy may cause nephrotoxicity with a subsequent drop in EPO production. ${ }^{39}$ Moreover, cisplatin increases ROS production and ROS in the kidney inhibits EPO synthesis, probably acting as negative regulator of EPO gene transcription. ${ }^{40,41}$ It is conceivable that combination chemotherapy further increases the risk of anemia. ${ }^{38}$ Hematotoxicity and anemia are also observed during anticancer treatment with targeted therapies, both in combination with conventional chemotherapy and alone. ${ }^{42}$ Generally, these agents cause low-grade anemia (grade 1-2); however, the mechanisms underlying their effects not well-established. ${ }^{42}$ PARP inhibitors are a new class of anticancer drugs recently developed for the treatment of ovarian, pancreatic and breast cancer. They may induce hematologic toxicity, potentially affecting all blood cell lines. In a meta-analysis of the adverse effects of olaparib from Phase II-III studies, $32 \%$ of patients with advanced ovarian cancer had all-grade anemia and 13\% had grade 3-4 anemia. ${ }^{43}$ Hematologic toxicity leads to the discontinuation of niraparib treatment in almost $15 \%$ of patients. ${ }^{44}$ The exact mechanism by which PARP inhibitors confer 


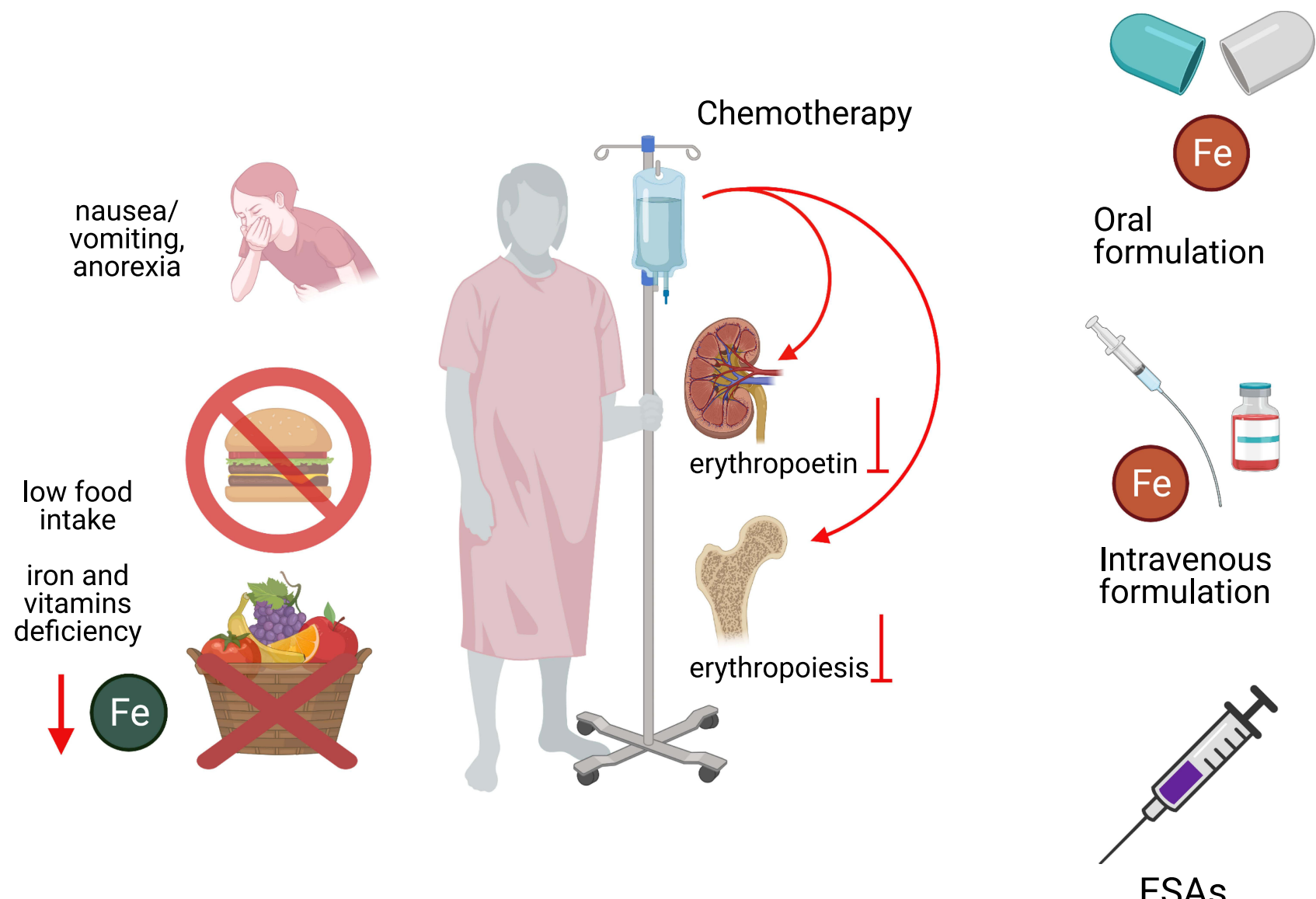

Figure 2 Pathogenesis of chemotherapy-induced anemia and therapeutic strategies. Chemotherapy-induced anemia is related to the toxic effect of anticancer treatments on bone marrow or to a nephrotoxic effect, which negatively influence EPO production. Additionally, anticancer treatments can induce gastro-enteric side effects, such as anorexia, nausea, and vomiting, and diarrhoea, which lead to iron and vitamins deficiency. Thus, treatment includes ESAs, iron therapy (oral or intravenous iron) and nutritional support. Figure was created in BioRender.com.

Abbreviations: Fe, iron; ESAs, erythropoiesis stimulating agents.

hematologic toxicity in humans is unknown. It may be related to genomic instability induced by these drugs; however, other molecular pathways could be involved, including oxidoreductive reactions and oxidative stress accumulation. PARP inhibitors approved for cancer therapy are not selective for different PARP isoforms. However, emerging evidence suggests that various PARP proteins govern different functions. ${ }^{45}$ For example, in mice, PARP-2 (and not PARP-1) is fundamental for the survival of erythroid precursors and hematopoiesis. ${ }^{46,47}$ Notably, PARP-2-deficient mice develop chronic anemia with low red blood cell counts, consequent to replicative stress in erythroid precursors, resulting in arrest in phase G2/M of the cell cycle. ${ }^{47}$ Instead, PARP-1 is involved in the regulation of iron metabolism via the inhibition of HFE gene expression, which finally controls hepcidin synthesis. $^{48}$
Chemotherapy can contribute to anemia via other mechanisms, beyond hematotoxicity. Indeed, anticancer treatments can induce gastro-enteric side effects, such as anorexia, nausea, and vomiting, and diarrhea (Figure 2). These side effects objectively decrease food intake or lead to a loss of nutrients, vitamins, and minerals, ultimately affecting erythropoiesis. ${ }^{26,49}$

In particular, we can affirm that chemotherapy-induced anemia can occur as pure adverse event in patients with early-stage cancer who were not anemic before starting chemotherapy. In this context, the gold standard treatment is erythropoiesis-stimulating agents (ESAs), which restore the stimulation of the bone marrow and erythroid precursors (Figure 2). If, instead, there is an underlying condition induced by advanced cancer, chemotherapy-induced anemia and cancer-related anemia overlap, and management should involve a multimodal approach accounting for the 
severity of anemia, the associated inflammatory state, the impairment in iron metabolism, and the nutritional status (Figure 1).

\section{Therapeutic Approaches for Anemia in Patients with Cancer}

The optimal treatment strategy for anemia depends on the exact underlying etiopathogenetic mechanisms, which, particularly in cancer-related anemia, generally involve IL-6-related inflammation with associated FID, oxidoreductive stress, and nutritional disorders. The careful characterization of anemia and associated clinical parameters is essential to establish management strategies, and other potentially remediable comorbidities should be identified and corrected. The initial evaluation of anemia in patients with cancer involves observations of signs and symptoms, exhaustive evaluations of blood counts, red blood cells, hemoglobin values, hematocrit and reticulocyte counts, and examinations of the nutritional status and potential deficiencies (based on iron stores, folates, and vitamin B12), such as deficiencies in renal function and endocrine function, to exclude comorbidities linked to anemia. ${ }^{26}$ It is critical to look for signs of chronic inflammation, such as high C-reactive prot ein (CRP), fibrinogen, and serum ferritin levels and low transferrin saturation. ${ }^{31,50,51}$ Evaluations of parameters related to iron metabolism (serum iron, ferritin, transferrin saturation percentage, and hepcidin, if possible) permits the detection of an iron deficiency (ID) or FID. ${ }^{52}$ Finally, the Glasgow Prognostic Score (GPS), obtained by the ratio between inflammation (CRP) and nutritional status (albumin), is of great value to clinicians, as it reflects the systemic inflammatorynutritional status of patients ${ }^{53}$ and is correlated with the severity of anemia. ${ }^{31}$

Treatments for anemia in patients with cancer aim to restore hemoglobin concentrations and red blood cell counts and thus to optimize blood and tissue oxygenation, resulting in improvements in energy and fatigue. Increased hemoglobin levels improve anemia-related symptoms and QoL, with the best benefits obtained for values of $\geq 12 \mathrm{~g} /$ dL. ${ }^{54}$ To ensure adequate erythropoiesis, the rebalancing of iron metabolism is essential. An iron deficiency, regardless of anemia, could itself contribute to fatigue. ${ }^{55}$ Importantly, iron homeostasis involves all hemoproteins, and these do not participate exclusively in oxygen transport and storage (hemoglobin and myoglobin) but also contribute to many fundamental metabolic pathways, such as energy production, protection from oxidative damage, and the regulation of inflammation. Cytochromes, catalases, peroxidases, and cyclooxygenase are just a few examples of hemoproteins. ${ }^{56}$

Therefore, we believe that an effective approach to cancer anemia must make use of multimodal interventions that include drugs and nutraceuticals capable of attenuating these conditions in a tailored manner. Conventional treatments available for anemia in cancer include ESAs, blood transfusions, and iron therapy. However, combined approaches including modulators of iron metabolism, nutritional support, or anti-inflammatory drugs should be considered. $^{2,57}$

\section{Red Blood Cell Transfusions}

Owing to the capacity to rapidly restore hemoglobin levels and tissue oxygenation, red blood cell transfusion remains the preferred treatment for patients with symptomatic severe anemia. It has been estimated that the infusion of 1 unit of concentrated erythrocytes is able to increase hemoglobin levels by $1 \mathrm{~g} / \mathrm{dL}$ and the hematocrit by approximately $3 \%{ }^{58}$ Thus, red blood cell transfusion confers rapid improvements in well-being and related QoL. ${ }^{59}$ However, it is more difficult in patients with cancer than in the general population to define the hemoglobin threshold under which transfusion therapy should be employed, and guidelines for red blood cell transfusions fail to provide specific recommendations in this setting. ${ }^{60}$ Generally, transfusions are recommended to restore severe anemia and obtain hemoglobin levels above $7-8 \mathrm{~g} / \mathrm{dL}$, with the minimum number of red blood cell units required. ${ }^{61}$ However, more recent guidelines agree that the use of erythrocyte transfusion should depend mainly on symptomatology, the rate of the hemoglobin decline, and individual risk factors, such as comorbidities and concomitant conditions. ${ }^{31,62,63}$ The presence of bleeding, ischemic diseases, the need for surgery, or the start of chemotherapy, for example, can prompt the choice of transfusion, even when hemoglobin values are above $8 \mathrm{~g} / \mathrm{dL}$.

There are some concerns regarding transfusion therapy. There is an intrinsic risk of acute adverse reactions and infection transmission. The introduction of several modern safety systems for blood supplies has considerably reduced the risk of infections, and particularly the risk of viral infections. ${ }^{64}$ However, the risks of hemolytic and allergic reactions, alloimmunization, iron and circulatory overload, and possible immunosuppression are not negligible. ${ }^{65}$ There is evidence for an increased risk of thromboembolic 
events in patients with cancer undergoing blood transfusions with an associated increased risk of mortality. ${ }^{66}$ There is a well-known thrombotic risk associated with cancer, especially in advanced-stages. Prophylactic anticoagulant use should reduce this risk, and studies are required to evaluate if routine low-molecular-weight heparin reduces the thrombotic risk and related mortality.

Notably, a relationship between the peri-operative need for erythrocyte transfusion and negative oncological outcomes has been reported for several types of cancer. Although the mechanisms underlying poor outcomes have yet to be determined, it is possible that the immunosuppressive effect of blood transfusions is involved. ${ }^{67-69}$ For these reasons, transfusion must be reserved for cases of severe symptomatic anemia and specific associated comorbidities.

\section{Erythropoiesis-Stimulating Agents}

Several randomized clinical trials and meta-analyses of cancer patients receiving chemotherapy have demonstrated the better efficacy of ESAs than the placebo in increasing hemoglobin levels and reducing erythrocyte transfusions. ${ }^{70-73}$ Among them, a Cochrane meta analysis published in 2012 on the efficacy of ESAs in patients with cancer, involving 91 trials with more than 20,000 participants, showed an overall significantly greater hematological response in subjects using ESAs versus controls (risk ratio $3.39,95 \%$ confidence interval $(\mathrm{CI}): 3.10-3.71)$ and a significant decrease in red blood cell transfusions (risk ratio 0.65 , 95\% CI: $0.62-0.68){ }^{73}$ The same meta-analysis also highlighted improvements in QoL, fatigue, and other anemia-related symptoms in patients receiving ESAs, according to the increase in hemoglobin concentrations. ${ }^{73}$ Although some trials have shown conflicting results concerning the changes in QoL in patients with cancer receiving ESAs, a recent systematic review concluded that ESAs are associated with a clinically important improvement in anemia-related symptoms. ${ }^{74}$ Thus, the effectiveness of ESAs for the treatment of chemotherapy-induced anemia is well supported.

ESAs act by stimulating the production of red blood cells in the bone marrow, leading to an increase in hemoglobin values obtainable in a few weeks. The therapeutic goal is the achievement and maintenance of hemoglobin values not requiring blood transfusions.

ESAs include recombinant human EPO (rHuEPO), and these have been approved for the treatment of anemia in cancer since the early 1990s. Epoetin- $\alpha$, epoetin- $\beta$, and darbepoetin- $\alpha$, modified recombinant EPOs, are also available for clinical use. ${ }^{75}$ These agents show similar effectiveness in clinical studies but have some pharmacokinetic differences. Darbepoetin- $\alpha$ boasts a longer half-life, which allows it to be administered every 2 or 3 weeks, although the time to achieve desired hemoglobin values may be longer than those for epoetin; agents with a shorter halflife require weekly administration. ${ }^{75,76}$ Original $\mathrm{rHuEPO}$ drugs are expensive, which has limited their use in many contexts. Biosimilar drugs share the same physicalchemical and biological properties and pharmaceutical form as the original drug and have demonstrated similar efficacy and safety in clinical trials, with reduced costs. ${ }^{77}$ Indeed, data available from studies on biosimilar epoetins were sufficient for their approval (both by the Food and Drug Administration-FDA- and European Medicines Agency-EMA) for clinical use with the same indications of original rHuEPOs. ${ }^{26,78,79}$

Of note, most clinical studies of ESAs efficacy have focused on subjects undergoing chemotherapy, irrespective of the treatment setting (adjuvant, induction chemotherapy with curative intent, or palliative). Thus, there is no clear evidence for the effectiveness of ESAs on different forms of anemia in patients with cancer. In cancer-related anemia without anticancer treatments, some studies have demonstrated significant increases in hemoglobin concentrations and hematologic responses after treatment with darbepoetin- $\alpha$ in comparison with those for placebo treatment. ${ }^{80,81}$ The incidence of transfusions in the treated arms was lower than that in untreated arms, although the difference was not significant. ${ }^{80,81}$ In a Cochrane meta-analysis, Tonia et al divided cases into subgroups based on the treatment type and found that patients with cancer and anemia not receiving chemotherapy benefit from ESAs administration, showing a positive hematologic response and changes in hemoglobin levels as well as a significant reduction in red blood cell transfusions. ${ }^{73}$ However, when target hemoglobin concentrations exceeded $12 \mathrm{~g} / \mathrm{dL}$, negative effects emerged, such as thrombotic events or improper disease progression. ${ }^{73,82-84}$ It could also be hypothesized that anemia is a symptom of the tolerance phase of the interaction between the tumor and host and acts as a defense mechanism in the final stages of the disease. It follows that anemia treatment would remove this defense and would attenuate cancer cell viability. However, this hypothesis has never been evaluated. The increase in thrombotic risk observed during ESAs treatment can be explained by the increased hematocrit 
percentages. ${ }^{73,82-86}$ Thus, it is necessary to evaluate other individual risk factors before starting ESAs. The risk of ESAs treatment appears to be lower when initial hemoglobin values are below $10 \mathrm{~g} / \mathrm{dL}$; however, additional evidence is needed to support this conclusion. ${ }^{82}$ In a recent meta-analysis evaluating risks of ESAs in patients with cancer including only randomized controlled trials in which treatment was started when hemoglobin concentrations were $<11 \mathrm{~g} / \mathrm{dL}$ and the target values were no more than $13 \mathrm{~g} / \mathrm{dL}$, thromboembolic events did not differ between ESAs treatment groups and controls. ${ }^{85}$ However, these data was not confirmed by previous meta-analyses. Owing to the lack of prospective randomized trials evaluating the role of antithrombotic therapy during ESAs use, actual guidelines do not recommend the default use of anti-coagulant prophylaxis to prevent thromboembolic events in patients with cancer undergoing ESAs treatment. $^{26,63,87}$ Nevertheless, since oncological subjects present an intrinsic pro-coagulant risk and chemotherapy can increase this risk, ${ }^{88}$ consistent thrombotic prophylaxis should be considered, especially when ESAs are used. Regarding neoplastic progression during ESAs, it has been suggested that these agents directly may stimulate tumor cell growth. Some evidence from in vitro studies supports this hypothesis. ${ }^{89,90}$ However, these effects have not been confirmed in vivo. Notably, recent clinical studies have confirmed that ESAs do not have an impact on oncological outcomes if given according to the label. ${ }^{91-94}$ Of note, the effects of various doses and overall ESAs exposure on patient outcomes remain open questions. Other potentially severe adverse events linked to ESAs include hypertensive events; accordingly, ESAs should be avoided in patients with uncontrolled hypertension and blood pressure values should be evaluated during treatment. Rare cases of thrombocytopenia and pure red cell aplasia have been reported. ${ }^{26,73,95}$

Considering these findings, the FDA restricted indications of ESAs to patients with cancer and anemia during chemotherapy with palliative intent, urging caution regarding the possibility of disease progression. ${ }^{62,63}$ Treatment might be started when hemoglobin levels are below $10 \mathrm{~g} /$ $\mathrm{dL}$, with the aim to reach $12 \mathrm{~g} / \mathrm{dL}$ and avoid red blood cell transfusions. Such warning has been shared by the guidelines published on this topic by the main International Societies (ASCO/ASH and NCCN), which indicate that ESAs are not recommended in patients with cancer not receiving myelosuppressive therapies. ${ }^{26,62,63,96}$ During ESAs treatment, hemoglobin values should be monitored every 1-2 weeks to evaluate the response. Dose reductions should be considered if hemoglobin levels increase by $1 \mathrm{~g} /$ $\mathrm{dL}$; a dose escalation is justified if there is no response (ie, $\mathrm{Hb}$ increase less than $1 \mathrm{~g} / \mathrm{dl}$ and $\mathrm{Hb}$ below $10 \mathrm{~g} / \mathrm{dl}$ ) in 4 or 6 weeks of epoetin or darbepoetin, respectively. ${ }^{26,62}$ If no hematologic effects emerge after 8 weeks, treatment should be stopped. ${ }^{26,62}$

\section{Iron Therapy}

The choice to include iron therapy in the management of patients with cancer and anemia must necessarily be guided by the evaluation of the iron status. Indeed, as already mentioned, anemia can be associated with an absolute ID, characterized by a depletion of the total body iron stores, or FID consequent to iron sequestration from the reticuloendothelial system, induced by chronic inflammation mechanisms and IL-6 via hepcidin pathways. Of course, iron supplements are required if ID is present, while new approaches that mobilize sequestered iron may be more suitable in FID.

ID is present in $30-60 \%$ of patients with cancer. ${ }^{25}$ When ID is present and no conditions impair enteric absorption, both oral and intravenous (IV) iron are efficient and recommended treatments. ${ }^{26}$ The majority of studies of the efficacy of iron treatment in the setting of chemotherapy-induced anemia have used IV administration. However, some factors may favor the use of oral iron, which is less expensive and more practical for home therapy. In cases with no FID and therefore with a deficiency not associated with inflammation, oral therapy may be used for the treatment of chemotherapy-induced anemia with associated ID. The choice of the administration route should depend on the onset and grade of ID and anemia as well as the likelihood of gastrointestinal absorption. ${ }^{53}$ Oral iron is administered as iron salts or iron carbohydrates, and the bivalent ferrous form shows better bioavailability. However, oral iron may have many limitations in cancer patients such as the compliance given it is required for several months to be effective as well as the poor tolerance and side effects including mainly nausea, vomiting, constipation, abdominal pain, and GI upset in a significant proportion of patients. ${ }^{97}$

Intravenous iron includes carbohydrate formulations, such as ferric gluconate, ferric sucrose, or low-molecularweight iron dextran, and glycan-coated drugs, such as ferric carboxymaltose, ferric isomaltoside, and iron ferumoxytol. $^{26,98}$ Carbohydrate ferric formulations require repeated administrations at low doses, while glycan-coated 
formulations, which are grouped as third generation IV iron compounds, can be infused at a single time at high doses. ${ }^{99}$ Common adverse events for IV preparations include dyspnea, hypo-/hypertension, headache, dizziness, and allergic reactions (observed mainly with iron dextran)..$^{98,100}$ Notably, the third generation IV iron formulations are proven to be safer with very rare side effects with high advantages in terms of improving compliance and tolerance, and bypassing the hepcidin-ferroportin pathway that controls iron absorption. ${ }^{97}$ These latter formulations do not require test dose to prevent/predict allergic reaction; however, they need to be given in a facility with resuscitation capabilities and with trained staff on managing anaphylaxis in case of rare reactions. ${ }^{97}$

Several clinical trials have evaluated the addition of IV iron to ESAs therapy versus ESAs alone for the treatment of chemotherapy-induced anemia. These trials have demonstrated synergistic effects of ESAs and IV iron. Iron strengthens the hematological response to ESAs by improving hemoglobin levels and times to achieve these levels and by reducing ESAs doses and red blood cells transfusions. ${ }^{53,101-104}$ Thus, the combination of ESAs and IV iron therapy is recommended in cancer patients with anemia undergoing chemotherapy with concomitant ID. ${ }^{26,63,96}$

Currently, the role of iron supplementation in patients with cancer-related anemia is more controversial. In this setting, FID can be present, where body iron is not available for erythropoiesis and is retained in the reticuloendothelial system. It is important to remember that FID is associated with limited gastrointestinal absorption; thus, oral iron is not applicable. In some cases, IV iron administration could force metabolic defects and partially support erythropoiesis. The best effects in terms of the hemoglobin response for IV iron plus ESAs or IV iron alone in patients with chemotherapy-induced anemia and FID have been observed when hepcidin concentrations are relatively low. ${ }^{105-107}$ Thus, hepcidin levels are a good predictor of the response to IV iron administration in patients with cancer and anemia with a high probability of FID. If hepcidin dosing is not available, analyses of the iron status (serum ferritin, transferrin saturation percentage) and inflammatory markers to detect absolute ID or FID can guide the use of iron therapy. As reported, in the case of FID, iron administration may not have the desired effects on the underlying, inflammation-induced alteration in iron metabolism. Furthermore, an iron overload can have harmful effects by increasing ROS production and oxidative stress, which can lead to mitochondrial and cellular damage. ${ }^{108}$ Novel approaches based on the mobilization of iron from the reticuloendothelial system and the antagonism of hepcidin function are under investigation and are expected to play an important role in the treatment of FID and cancer-related anemia.

\section{Experimental Drugs Targeting Iron Metabolism Lactoferrin}

As innovative modulator of iron metabolism, lactoferrin, an iron-binding protein belonging to the transferrin family with antibacterial, antioxidant, and immunomodulatory properties, has yielded interesting results with respect to the treatment of cancer-related anemia. ${ }^{109}$ In a randomized clinical trial of patients with cancer-related anemia starting chemotherapy, we compared the efficacy of rHuEPO combined with IV iron or oral lactoferrin for the treatment of anemia. ${ }^{10}$ In both arms, hemoglobin concentrations increased significantly; however, as added value, patients treated with lactoferrin exhibited a reduction in ferritin levels while the iron arm showed increased levels. These data confirm that lactoferrin functions as modulator of iron metabolism and is therefore useful for the management of anemia associated with iron dysregulation. Moreover, patients with cancer could benefit from the antioxidant and immunomodulatory effects of lactoferrin, and further studies on this topic are needed.

\section{Hepcidin Antagonists}

As described above, IL-6 and hepcidin contribute to alterations in iron metabolism in states of chronic inflammation. Experimental drugs under investigation for the treatment of anemia associated with iron dysregulation generally aim to reduce hepcidin production, to neutralize its biological effect, or to inhibit its action on ferroportin. ${ }^{98}$ These drugs are also promising in combination with ESAs, which increase the availability of endogenous iron and enhance erythropoiesis. Among hepcidin antagonists, two promising drugs that act as hepcidin-neutralizing agents are now under evaluation in clinical trials. A neutralizing monoclonal anti-hepcidin antibody, LY2787106, stimulates erythropoiesis and modulates serum iron in animal models of inflammation-induced anemia. ${ }^{111}$ A phase-I study of the pharmacokinetics, safety and efficacy of this compound in cases of anemia with non-myeloid advanced cancer and high hepcidin concentrations showed that LY2787106 was well-tolerated and induced dose-dependent increases in 
serum iron and transferrin saturation. ${ }^{112}$ A second hepcidin antagonist, NOX-H94 or lexaptepid, is a structured mirrorimage L-enantiomeric oligonucleotide created to bind to and inhibit hepcidin. ${ }^{113}$ In a phase-IIa study of patients with cancer and anemia, this drug increased hemoglobin levels in 5 of 12 participants and reduced ferritin concentrations. $^{114}$

\section{Prolyl Hydroxylase Inhibitors}

Another experimental class of drugs is prolyl hydroxylase inhibitors, which protect HIFs from degradation and, consequently, increase tissue concentrations. HIFs are transcription factors that act in conditions of low tissue oxygenation, mediating the cellular response to hypoxia. In the kidney, HIF-2 $\alpha$ directly promotes EPO synthesis. HIFs can also promote iron release from enterocytes and macrophages, respectively, via the increased transcription of ferroportin and hemeoxygenase-1 (involved in iron recovery from macrophages hemoglobin degradation). ${ }^{115}$ Several prolyl hydroxylase inhibitors have been tested in phase-II and phase-III trials as orally active drugs, mainly for the treatment of anemia induced by chronic kidney disease. ${ }^{116,117}$ To date, no studies have evaluated the effects of this pharmacological class on anemia in patients with cancer owing to possible effects on tumor growth. Indeed, HIF stimulates angiogenesis via the transcription of pro-angiogenetic factors, such as vascular endothelialgrowth factor (VEGF). In a mouse model of VEGFsensitive breast cancer, a prolyl hydroxylase inhibitor had no effect on tumor development or progression. ${ }^{118}$ Further studies of the oncologic safety of prolyl hydroxylase inhibitors are required before they are tested in patients with cancer.

\section{Anti-IL-6 Antibodies}

Several malignancies are associated with IL-6 overexpression, and IL-6-mediated inflammatory pathways are correlated with cancer morbidity and mortality. For this reason, the blockade of IL-6 has been investigated as a possible anticancer treatment. Monoclonal antibodies against IL-6 or its receptor have been introduced for cancer therapy as single agents or in combination with chemotherapy. Data from preclinical studies and experimental trials, particularly in patients with advanced ovarian or lung cancer, revealed that, in addition to the anticancer effects, monoclonal anti-IL-6 antibodies can increase hemoglobin levels and improve anemia. ${ }^{119,120}$

\section{Experimental Drugs Targeting Activin II Receptor Signals}

Activin type II receptors, belonging to the family of serine/ threonine kinase receptors, bind to a subgroup of transforming growth factor- $\beta$ (TGF- $\beta$ ) and once activated, induce intracellular signals leading to the activation of SMAD2/3. The SMAD2/3 pathway is involved in proliferation and differentiation ${ }^{121}$ and its activation in erythroid stem cells has an inhibitory effect on these processes. ${ }^{122,123}$ Therefore, the TGF- $\beta$ /activin II receptor pathway is a candidate therapeutic target to improve erythropoiesis. Among developed drugs targeting activin II receptor signaling, two fusion proteins obtained from the union of the activin II receptor extracellular domain and the $\mathrm{Fc}$ fragment of human IgG have been tested in clinical trials (luspatercept and sotatercept). These drugs act by binding to activin II receptor ligands, thereby limiting the negative effect of erythropoiesis of the SMAD pathway and increasing erythroid differentiation. ${ }^{124,125}$ Luspatercept (ACE-536) has been approved by the FDA for the treatment of anemia in patients with $\beta$-thalassemia who require frequent red blood cell transfusions. ${ }^{126}$ PhaseII and phase-III studies on the safety and efficacy of this compound for the treatment of anemia in myelofibrosis and myelodysplastic syndrome have been started. ${ }^{127}$ Recently, the results from a Phase III study on patients affected by transfusion-dependent low risk myelodysplastic syndrome with ring sideroblasts, who were refractory to or unlikely to respond to ESAs or who had discontinued such agents owing to an adverse event, demonstrated that luspatercept reduced the severity of anemia and improved transfusion independence. ${ }^{128}$ These results resulted in resulted in approval by both the US FDA and EMA. ${ }^{129}$ Sotatercept (ACE-011) has been tested and is under investigation in pre-marketing clinical trials for various uses, including thalassemia and other congenital forms of anemia, myelodysplastic syndrome, multiple myeloma, end stage renal disease, and pulmonary arterial hypertension, with results indicating good tolerability and efficacy. ${ }^{124,130}$ Interestingly, a Phase II placebo-controlled study evaluated sotatercept for the treatment of anemia associated with platinum-based chemotherapy in patients with advanced/metastatic solid tumors. ${ }^{131}$ Various different doses were administered subcutaneously every 28 or 42 days for a maximum of four doses; 55 patients were enrolled, of which 50 received more than one dose of sotatercept and 5 received the placebo. Unfortunately, the 
study was stopped early owing to a slow recruitment rate. The preliminary results indicated that mean hemoglobin levels increased $1 \mathrm{~g} / \mathrm{dL}$ or more for the $66.7 \%$ of patients receiving $15 \mathrm{mg}$ sotatercept and for the $38.9 \%$ of patients receiving $30 \mathrm{mg}$; the safety profile was comparable to that of placebo group. ${ }^{131}$ These data, even if limited, highlight the potential clinical value of sotatercept for the treatment of anemia in patients with cancer.

\section{Nutritional Support}

As explained above, in cancer-related anemia, inflammation and metabolic changes seem to play crucial roles in the maintenance of low hemoglobin levels and weak erythropoietic responses. Several nutrients (such as amino acids and vitamins, mainly in group B) in addition to iron are essential for the synthesis of heme and hemoglobin and for erythropoiesis. ${ }^{132}$ Furthermore, tumor-induced chronic inflammation is related to changes in energy metabolism towards an increase in calorie expenditure and is worsened by the decrease in nutrient intake under anorexia. ${ }^{133,134}$ These observations emphasize the importance of careful evaluations of the nutritional status in patients with cancer and anemia and secondarily suggest that antioxidants, anti-inflammatory substances, and other specific nutrients may play key roles in the management of this condition. Notably, substances with anti-inflammatory /antioxidant activity are widely used in clinical practice. Rational supplementation should focus on nutraceuticals with efficacy supported by scientific evidence. Representative substances that have been studied in the context of chronic inflammatory or cancer anemia are described below.

\section{Polyphenols}

Polyphenols are plant-derived compounds with antioxidant, anti-inflammatory, and anti-infective properties. Clinical findings as well as in vitro and in vivo studies have shown that polyphenols can reduce pro-inflammatory cytokine production, ${ }^{135,136}$ downregulate pro-oxidant enzymes, and upregulate antioxidant enzymes. ${ }^{137}$ Curcumin is a well-known polyphenol extracted from turmeric. In addition to the cytokine-reducing effects common to other polyphenols, curcumin inhibits hepcidin transcription in vitro. ${ }^{138}$ In a randomized placebo-controlled trial, the administration of a single oral dose of $6 \mathrm{~g}$ curcuma induced a significant decrease in hepcidin levels. ${ }^{139}$ Moreover, curcumin acts as an iron chelator in cell cultures and in mouse models. ${ }^{140}$ Accordingly, curcumin may be useful in anemia characterized by iron overload or chronic inflammation, and a clinical trial evaluated the effect of curcumin on iron parameters in patients with thalassemia major, showing a decrease in serum iron, despite no changes in hepcidin levels. ${ }^{141}$ In 2015, we published two case reports describing the successful management of two patients with anemia, one affected by advanced hormone-resistant prostate cancer and one with myelofibrosis and cachexia; using a multimodal approach consisting in rHuEPO, lactoferrin, curcumin, L-carnitine, and celecoxib, subjects showed improvements in hemoglobin levels, body weight, lean mass, fatigue, and QoL. ${ }^{142,143}$

\section{Carnitine}

L-Carnitine is an amino acid derivative synthesized by the body that acts as fatty acid transporter in the mitochondrion, allowing the production of energy by $\beta$ oxidation. Low carnitine levels are associated with fatigue in some cases, including in patients with cancer. ${ }^{144,145}$ Thus, several trials have evaluated L-carnitine supplementation for the treatment of cancerassociated fatigue. We have previously conducted a randomized controlled clinical trial comparing megestrol acetate alone or with L-carnitine, celecoxib, and antioxidants for the management of cachexia induced by gynecological cancers. We found more pronounced improvements of lean body mass, fatigue, and QoL in the experimental arm, along with significative decreases in inflammatory and oxidative stress parameters. ${ }^{34}$ Our results underline the usefulness of anti-inflammatory and antioxidant support for a more complete approach in cancer patients with advanced disease. In this regard, it must be remembered that fatigue is an extremely frequent symptom of advanced neoplasms and often accompanies cancer-related anemia. Another placebo-controlled study confirmed the positive role of carnitine supplementation in reducing fatigue, as evaluated by the Functional Assessment of Cancer Therapy-Anemia, in patients with advanced cancer with L-carnitine deficiencies. ${ }^{146}$ Improvements in fatigue contribute to the general wellbeing of patients.

\section{Vitamins}

Some vitamins, such as folic acid (vitamin B9) or cyanocobalamin (vitamin B12), are indispensable for erythropoiesis and heme synthesis to the extent that deficiencies result in anemia. In view of the antioxidant effects and other 
beneficial properties, several vitamins can be useful components of an integrated treatment strategy for anemia. Vitamin B9 and B12 are both enzymatic cofactors in nucleic acid synthesis; folic acid is also involved in amino acid metabolism and in oxidoreductive reactions. ${ }^{147}$ Among other group $\mathrm{B}$ vitamins, thiamine (vitamin B1) is essential in energetic metabolism and glucose oxidation, as a cofactor for enzymes involved in the Krebs cycle. ${ }^{148}$ Vitamin B6 is involved in basic cellular metabolism, amino acid and protein synthesis, and the neutralization of free oxygen radicals. $^{149}$ Interestingly, vitamin D has anti-inflammatory and immunomodulatory activities linked, for example, to its ability to

Table I Management of Chemotherapy- and Cancer- Related Anemia

\begin{tabular}{|c|c|c|c|c|c|}
\hline & $E S A s^{a, b, c}$ & Iron Supplementation & $\begin{array}{l}\text { Other } \\
\text { Supportive } \\
\text { Agents }\end{array}$ & Novel Agents & References \\
\hline $\begin{array}{l}\text { Absolute iron } \\
\text { deficiency (ID): } \\
\text { Ferritin }<30 \\
\mathrm{ng} / \mathrm{mL} \text { and } \\
\text { TSAT < } 20 \% \\
\text { CRP normal } \\
\text { value }\end{array}$ & $\begin{array}{l}\text { ESAs could } \\
\text { be used after } \\
\text { iron } \\
\text { deficiency } \\
\text { correction }^{26}\end{array}$ & $\begin{array}{l}\text { Oral iron supplementation or } \\
\text { IV iron formulations (the } \\
\text { choice depends on the } \\
\text { severity of anemia and } \\
\text { gastrointestinal } \\
\text { absorption) }^{26,62,63,96}\end{array}$ & $\begin{array}{l}\text { Nutritional } \\
\text { support (folate, } \\
\text { vitamins B,C,D, } \\
\text { polyphenols, } \\
\text { L-carnitine, } \\
\text { aminoacids) }^{156}\end{array}$ & $\begin{array}{l}\text { Oral iron liposomal } \\
\text { formulation }{ }^{161} \\
\text { Third generation IV iron } \\
\text { formulations (ie, ferric } \\
\text { carboxymaltose) }^{97,162,163}\end{array}$ & {$[26,62,63,96,97,156,161-163]$} \\
\hline $\begin{array}{l}\text { Possible } \\
\text { functional iron } \\
\text { deficiency } \\
\text { (FID): Ferritin } \\
30-500 \mathrm{ng} / \mathrm{mL} \\
\text { and TSAT < } 50 \% \\
\text { High CRP }\end{array}$ & $\mathrm{ESAs}^{26,62,63,96}$ & $\begin{array}{l}\text { IV iron supplementation; oral } \\
\text { iron is not indicated for } \\
\text { gastrointestinal } \\
\text { malasorbption }^{26,62,63,96}\end{array}$ & $\begin{array}{l}\text { Anti- } \\
\text { inflammatory } \\
\text { agents } \\
\text { Nutritional } \\
\text { support (folate, } \\
\text { vitamins B,C,D, } \\
\text { polyphenols, } \\
\text { L-carnitine, } \\
\text { aminoacids) }^{156}\end{array}$ & $\begin{array}{l}\text { Third generation IV iron } \\
\text { formulations (ie, ferric } \\
\text { carboxymaltose) }\end{array}$ & {$[26,62,63,96,97,156,162,163]$} \\
\hline $\begin{array}{l}\text { Functional iron } \\
\text { deficiency } \\
\text { (FID): Ferritin } \\
>500-800 \text { ng/ } \\
\mathrm{mL} \text { and TSAT } \\
<50 \% \\
\text { High CRP }\end{array}$ & $\mathrm{ESAs}^{26,62,63,96}$ & $\begin{array}{l}\text { Supplementation with iron } \\
\text { mobilizing agents such as } \\
\text { lactoferrin should be } \\
\text { preferred to IV iron } \\
101,110\end{array}$ & $\begin{array}{l}\text { Anti- } \\
\text { inflammatory } \\
\text { agents } \\
\text { Nutritional } \\
\text { support (folate, } \\
\text { vitamins B,C,D, } \\
\text { polyphenols, } \\
\text { L-carnitine, } \\
\text { aminoacids) }^{156}\end{array}$ & Hepcidin antagonists ${ }^{114}$ & {$[26,62,63,96,101,110,114,156]$} \\
\hline $\begin{array}{l}\text { Iron overload: } \\
\text { Ferritin }>800 \\
\mathrm{ng} / \mathrm{mL} \text { and } \\
\text { TSAT }>50 \% \\
\text { High CRP }\end{array}$ & $\mathrm{ESAs}^{26,62,63,96}$ & $\begin{array}{l}\text { Supplementation with iron } \\
\text { mobilizing agents }{ }^{101,110} \\
\text { Oral or IV Iron } \\
\text { supplementation is not } \\
\text { indicated }^{26}\end{array}$ & $\begin{array}{l}\text { Anti- } \\
\text { inflammatory } \\
\text { agents } \\
\text { Nutritional } \\
\text { support (folate, } \\
\text { vitamins B,C,D, } \\
\text { polyphenols, } \\
\text { L-carnitine, }^{\text {aminoacids) }}\end{array}$ & Hepcidin antagonist ${ }^{114}$ & {$[26,62,63,96,101,110,114,156]$} \\
\hline
\end{tabular}

Notes: ${ }^{a}$ ESAs are indicated only patients undergoing myelosuppressive treatment with palliative intent when $\mathrm{Hb}<10 \mathrm{~g} / \mathrm{dl}{ }^{26,62,63,96} \mathrm{~b}$ ESAs could be used in presence of chronic kidney disease (moderate to severe) independently from concomitant chemotherapy according to specific guidelines. ${ }^{26} \mathrm{c}$ In every category red blood cell transfusion may be indicated when $\mathrm{Hb}$ levels are $<7-8 \mathrm{~g} / \mathrm{dl}$; it may be an option even at higher $\mathrm{Hb}$ levels $(\mathrm{Hb}<10 \mathrm{~g} / \mathrm{dl})$ depending on anemia-related symptoms and performance status, the severity of anemia and rate of $\mathrm{Hb}$ decline, and individual risk factors such as comorbidities (ie, bleeding, surgery, cardiovascular and ischemic disease). ${ }^{26,62,63}$ References are indicated by superscript near to each statement and also in the last column.

Abbreviations: ESAs, erythropoiesis-stimulating agents; ID, iron deficiency; TSAT, transferrin saturation; CRP, C-reactive protein; IV, intravenous; FID, functional iron deficiency. 
reduce cytokine and chemokine secretion. ${ }^{150}$ Furthermore, it could have a role in the regulation of iron homeostasis. Notably, vitamin D-mediated reductions in IL-6 levels can affect hepcidin synthesis. In vitro studies have shown that vitamin $\mathrm{D}$ use is associated with a reduction in hepcidin and a rise in ferroportin expression in macrophages. ${ }^{151}$ Clinical studies have revealed an association between chronic inflammatory diseases characterized by high hepcidin levels and a vitamin D deficiency. ${ }^{152,153}$ Moreover, vitamin D administration decreases hepcidin concentrations in healthy adults ${ }^{154}$ and hepcidin and inflammatory markers in patients with inflammatory bowel diseases. ${ }^{155}$ These findings suggest that vitamin D could alleviate FID and related anemia in patients with cancer. A case-control study of patients with anemia due to congestive heart failure and catabolic disorder (attributed to a low albumin concentration), suggesting chronic inflammation, compared the use of IV standard iron therapy with iron plus supplementation with essential amino acids, group B vitamins (B1, B6, and B9), and vitamin $\mathrm{D}$, for anemia treatment. ${ }^{156}$ The increase in hemoglobin concentrations was significantly more rapid with supplementation than with iron alone, demonstrating the efficacy of integrated approaches to treat anemia in chronic inflammation. Finally, ascorbic acid (vitamin C) has relevant properties, including potent antioxidant activity and a role in iron metabolism, with the ability to enhance iron adsorption in the gut $^{157}$ and regulate cellular iron uptake. $^{158}$ In hepatocyte cultures, vitamin $\mathrm{C}$ induced a decrease in hepcidin production and upregulated EPO receptor expression. ${ }^{159}$ In patients with advanced chronic kidney failure and EPO-resistant anemia, the addition of ascorbic acid to standard therapy with ESAs and IV iron leads to greater increases in hemoglobin levels and transferrin saturation compared to ESAs plus iron alone and a decrease in CRP concentrations, likely by improving ESA responsiveness. ${ }^{160}$

The same benefits achieved by supplementation could be obtained in patients with cancer and anemia. Combinations between these substances and standard therapies for anemia induced by cancer chemotherapies and cancer-associated chronic inflammation should be evaluated in detail.

\section{Conclusion}

Anemia in patients with cancer is a cause for concern owing to its prevalence and its effects on health status, QoL, and prognosis. In chemotherapy-induced anemia, anticancer treatments exert toxic effects on the bone marrow and, in some cases, the kidney. However, patients with cancer more frequently suffer from the more complex type of anemia due to chronic inflammation in response to the tumor, oxidative stress, malnutrition, and systemic metabolic changes. Thus, the treatment of cancer-related anemia should be individualized basing on the severity, iron homeostasis, nutritional status (including evaluation of folate, vitamin B12, albumin, and GPS) and, surely, associated inflammation. ESA and iron supplementation are the cornerstones of the treatment of anemia in cancer patients with specific indication based on the different treatment setting as reported in Table 1. Of relevance, we think that the best therapeutic approach is ultimately the correction of all pathogenetic mechanisms by a multitargeted strategy using in the most appropriate way the therapeutic devices indicated in this review.

\section{Abbreviations}

CI, confidence interval; CRP, C-reactive protein; CTCAE, Common Terminology Criteria for Adverse Events; EMA, European Medicines Agency; EPO, erythropoietin; ESAs, erythropoiesis-stimulating agents; FDA, Food and Drug Administration; FID, functional iron deficiency; GPS, Glasgow Prognostic Score; HIF, hypoxia-inducible factor; ID, iron deficiency; IL, interleukin; IFN- $\gamma$, interferon gamma; IV, intravenous; NCI, National Cancer Institute; QoL, quality of life; rHuEPO, recombinant human erythropoietin; ROS, reactive oxygen species; TNF- $\alpha$, tumor necrosis factor alpha; VEGF, vascular endothelial-growth factor.

\section{Acknowledgments}

Work supported by Associazione Sarda per la Ricerca in Ginecologia Oncologica. The authors would thank Dr Paolo Cannas, General Manager of the "Azienda di Rilievo Nazionale ad Alta Specializzazione G. Brotzu", for the encouragement in the development of this research. The authors thank Dr Martina Mura for her technical assistance.

\section{Author Contributions}

All authors made a significant contribution to the work reported, in the conception, study design, execution, acquisition of data, analysis and interpretation; took part in drafting, revising or critically reviewing the article; gave final approval of the version to be published; have agreed on the journal to which the article has been submitted; and agree to be accountable for all aspects of the work. 


\section{Disclosure}

The authors declare no conflicts of interest in this work.

\section{References}

1. McLean E, Cogswell M, Egli I, Wojdyla D, de Benoist B. Worldwide prevalence of anaemia, WHO vitamin and mineral nutrition information system, 1993-2005. Public Health Nutr. 2009;12(4):444-454. doi:10.1017/S1368980008002401

2. Madeddu C, Gramignano G, Astara G, et al. Pathogenesis and treatment options of cancer related anemia: perspective for a targeted mechanism-based approach. Front Physiol. 2018;9:1294. doi:10.3389/fphys.2018.01294

3. Birgegård G, Aapro MS, Bokemeyer C, et al. Cancer-related anemia: pathogenesis, prevalence and treatment. Oncology. 2005;68(Suppl 1):3-11. doi:10.1159/000083128

4. Schwartz RN. Anemia in patients with cancer: incidence, causes, impact, management, and use of treatment guidelines and protocols. Am J Health Syst Pharm. 2007;64(3Suppl 2):S5-S13; quiz S28-S30. doi:10.2146/ajhp060601

5. Wu Y, Aravind S, Ranganathan G, Martin A, Nalysnyk L. Anemia and thrombocytopenia in patients undergoing chemotherapy for solid tumors: a descriptive study of a large outpatient oncology practice database, 2000-2007. Clin Ther. 2009;31(Pt 2):2416-2432. doi:10.1016/j.clinthera.2009.11.020

6. Knight K, Wade S, Balducci L. Prevalence and outcomes of anemia in cancer: a systematic review of the literature. Am J Med. 2004;116 (Suppl7A):11S-26S. doi:10.1016/j.amjmed.2003.12.008

7. Melo-Alvim C, Miguel-Semedo P, Paiva RS, et al. Pretreatment hemoglobin level as a prognostic factor in patients with locally advanced head and neck squamous cell carcinoma. Rep Pract Oncol Radiother. 2020;25(5):768-774. doi:10.1016/j.rpor.2020.07.002

8. An MS, Yoo JH, Kim $\mathrm{KH}$, et al. T4 stage and preoperative anemia as prognostic factors for the patients with colon cancer treated with adjuvant FOLFOX chemotherapy. World $J$ Surg Oncol. 2015;13:64. doi:10.1186/s12957-015-0488-7

9. Shin NR, Lee YY, Kim SH, et al. Prognostic value of pretreatment hemoglobin level in patients with early cervical cancer. Obstet Gynecol Sci. 2014;57(1):28-36. doi:10.5468/ogs.2014.57.1.28

10. Zhang Y, Chen Y, Chen D, et al. Impact of preoperative anemia on relapse and survival in breast cancer patients. BMC Cancer. 2014;14:844. doi:10.1186/1471-2407-14-844

11. Obermair A, Petru E, Windbichler G, et al. Significance of pretreatment serum hemoglobin and survival in epithelial ovarian cancer. Oncol Rep. 2000;7:639-644. doi:10.3892/or.7.3.639

12. Lee WR, Berkey B, Marcial V, et al. Anemia is associated with decreased survival and increased locoregional failure in patients with locally advanced head and neck carcinoma: a secondary analysis of RTOG 85-27. Int J Radiat Oncol Biol Phys. 1998;42 (5):1069-1075. doi:10.1016/S0360-3016(98)00348-4

13. Grant DG, Hussain A, Hurman D. Pre-treatment anaemia alters outcome in early squamous cell carcinoma of the larynx treated by radical radiotherapy. J Laryngol Otol. 1999;113(9):829-833. doi:10.1017/S0022215100145323

14. Prosnitz RG, Yao B, Farrell CL, Clough R, Brizel DM. Pretreatment anemia is correlated with the reduced effectiveness of radiation and concurrent chemotherapy in advanced head and neck cancer. Int $J$ Radiat Oncol Biol Phys. 2005;61 (4):1087-1095. doi:10.1016/j.ijrobp.2004.07.710

15. Fuso L, Mazzola S, Marocco F, et al. Pretreatment serum hemoglobin level as a predictive factor of response to neoadjuvant chemotherapy in patients with locally advanced squamous cervical carcinoma: a preliminary report. Gynecol Oncol. 2005;99(3 Suppl 1):S187-S191. doi:10.1016/j.ygyno.2005.07.079
16. Zhu W, Xu B. Association of pretreatment anemia with pathological response and survival of breast cancer patients treated with neoadjuvant chemotherapy: a population-based study. PLoS One. 2015;10(8):e0136268. doi:10.1371/journal.pone.0136268

17. Harris AL. Hypoxia-a key regulatory factor in tumour growth. Nat Rev Cancer. 2002;2(1):38-47. doi:10.1038/nrc704

18. Holzner B, Kemmler G, Greil R, et al. The impact of hemoglobin levels on fatigue and quality of life in cancer patients. Ann Oncol. 2002;13(6):965-973. doi:10.1093/annonc/mdf122

19. Ludwig H, Müldür E, Endler G, Hübl W. Prevalence of iron deficiency across different tumors and its association with poor performance status, disease status and anemia. Ann Oncol. 2013;24(7):1886-1892. doi:10.1093/annonc/mdt118

20. Owusu C, Cohen HJ, Feng T, et al.; Cancer and Aging Research Group (CARG). Anemia and functional disability in older adults with cancer. J Natl Compr Canc Netw. 2015;13(10):1233-1239. doi:10.6004/jncen.2015.0152

21. Spivak JL. Cancer-related anemia: its causes and characteristics. Semin Oncol. 1994;21(2 Suppl 3):3-8.

22. Adamson JW. The anemia of inflammation/malignancy: mechanisms and management. Hematol Am Soc Hematol Educ Program. 2008;2008(1):159-165. doi:10.1182/asheducation-2008.1.159

23. Spivak JL. The anaemia of cancer: death by a thousand cuts. Nat Rev Cancer. 2005;5(7):543-555. doi:10.1038/nrc1648

24. Miller CB, Jones RJ, Piantadosi S, Abeloff MD, Spivak JL. Decreased erythropoietin response in patients with the anemia of cancer. N Engl J Med. 1990;322(24):1689-1692. doi:10.1056/ NEJM199006143222401

25. Aapro M, Österborg A, Gascón P, Ludwig H, Beguin Y. Prevalence and management of cancer-related anaemia, iron deficiency and the specific role of i.v. iron. Ann Oncol. 2012;23 (8):1954-1962. doi:10.1093/annonc/mds112

26. National Comprehensive Cancer Network. NCCN Clinical Practice Guidelines in Oncology. Hematopoietic Growth Factors. Version 2; March 23, 2021. Available from: https:// www.nccn.org/professionals/physician_gls/pdf/growthfactors.pdf. Accessed April 13, 2021.

27. Spivak JL. Iron and the anemia of chronic disease. Oncology (Huntingt). 2002;16(9 Suppl 10):25-33.

28. Faquin WC, Schneider TJ, Goldberg MA. Effect of inflammatory cytokines on hypoxia-induced erythropoietin production. Blood. 1992;79(8):1987-1994. doi:10.1182/blood.V79.8.1987.1987

29. Jewell UR, Kvietikova I, Scheid A, Bauer C, Wenger RH, Gassmann M. Induction of HIF-1 alpha in response to hypoxia is instantaneous. FASEB J. 2001;15(7):1312-1314. doi:10.1096/ fj.00-0732fje

30. Lang F, Abed M, Lang E, Föller M. Oxidative stress and suicidal erythrocyte death. Antioxid Redox Signal. 2014;21(1):138-153. doi:10.1089/ars.2013.5747

31. Macciò A, Madeddu C, Gramignano G, et al. The role of inflammation, iron, and nutritional status in cancer-related anemia: results of a large, prospective, observational study. Haematologica. 2015;100(1):124-132. doi:10.3324/ haematol.2014.112813

32. Andrews NC. Anemia of inflammation: the cytokine-hepcidin link. J Clin Invest. 2004;113(9):1251-1253. doi:10.1172/ JCI21441

33. Ganz T. Hepcidin, a key regulator of iron metabolism and mediator of anemia of inflammation. Blood. 2003;102(3):783-788. doi:10.1182/blood-2003-03-0672

34. Macciò A, Madeddu C, Gramignano G, et al. A randomized phase III clinical trial of a combined treatment for cachexia in patients with gynecological cancers: evaluating the impact on metabolic and inflammatory profiles and quality of life. Gynecol Oncol. 2012;124(3):417-425. doi:10.1016/j. ygyno.2011.12.435 
35. U.S. Department of Health and Human Services. Common Terminology Criteria for Adverse Events (CTCAE). Version 5.0; November 27, 2017. Available from: https://ctep.cancer.gov/pro tocoldevelopment/electronic_applications/docs/ctcae_v5_quick reference_5x7.pdf. Accessed February 02, 2021.

36. Dalton JD, Bailey NP, Barrett-Lee PJ, O'Brien MER. Multicenter UK audit of anemia in patients receiving cytotoxic chemotherapy [abstract]. Proc ASCO. 1998;17:418a.

37. Cheng K, Zhao F, Gao F, et al. Factors potentially associated with chemotherapy-induced anemia in patients with solid cancers. Asian Pac J Cancer Prev. 2012;13(10):5057-5061. doi:10.7314/ APJCP.2012.13.10.5057

38. Groopman JE, Itri LM. Chemotherapy-induced anemia in adults: incidence and treatment. $J$ Natl Cancer Inst. 1999;91 (19):1616-1634. doi:10.1093/jnci/91.19.1616

39. Perazella MA, Moeckel GW. Nephrotoxicity from chemotherapeutic agents: clinical manifestations, pathobiology, and prevention/therapy. Semin Nephrol. 2010;30(6):570-581. doi:10.1016/j.semnephrol.2010.09.005

40. Neumcke I, Schneider B, Fandrey J, Pagel H. Effects of pro- and antioxidative compounds on renal production of erythropoietin. Endocrinology. 1999;140(2):641-645. doi:10.1210/ endo.140.2.6529

41. Macciò A, Madeddu C. Cisplatin: an old drug with a newfound efficacy - from mechanisms of action to cytotoxicity. Expert Opin Pharmacother. 2013;14(13):1839-1857. doi:10.1517/ 14656566.2013.813934

42. Barni S, Cabiddu M, Guarneri P, Lonati V, Petrelli F. The risk for anemia with targeted therapies for solid tumors. Oncologist. 2012;17(5):715-724. doi:10.1634/theoncologist.2012-0024

43. Ruiz-Schutz VC, Gomes LM, Mariano RC, et al. Risk of fatigue and anemia in patients with advanced cancer treated with olaparib: a meta-analysis of randomized controlled trials. Crit Rev Oncol Hematol. 2019;141:163-173. doi:10.1016/j. critrevonc.2019.06.012

44. Moore KN, Mirza MR, Matulonis UA. The poly (ADP ribose) polymerase inhibitor niraparib: management of toxicities. Gynecol Oncol. 2018;149(1):214-220. doi:10.1016/j. ygyno.2018.01.011

45. Wahlberg E, Karlberg T, Kouznetsova E, et al. Family-wide chemical profiling and structural analysis of PARP and tankyrase inhibitors. Nat Biotechnol. 2012;30(3):283-288. doi:10.1038/ nbt. 2121

46. Farrés J, Martín-Caballero J, Martínez C, et al. Parp-2 is required to maintain hematopoiesis following sublethal $\gamma$-irradiation in mice. Blood. 2013;122(1):44-54. doi:10.1182/blood-2012-12472845

47. Farrés J, Llacuna L, Martin-Caballero J, et al. PARP-2 sustains erythropoiesis in mice by limiting replicative stress in erythroid progenitors. Cell Death Differ. 2015;22(7):1144-1157. doi:10.1038/cdd.2014.202

48. Pelham C, Jimenez T, Rodova M, Rudolph A, Chipps E, Islam MR. Regulation of HFE expression by poly(ADP-ribose) polymerase-1 (PARP1) through an inverted repeat DNA sequence in the distal promoter. Biochim Biophys Acta. 2013;1829 (12):1257-1265. doi:10.1016/j.bbagrm.2013.10.002

49. Gao F, Cheng K, Zhao F, et al. Prevalence and characteristics of anemia in patients with solid cancers at diagnosis in southwest China. Asian Pac J Cancer Prev. 2011;12(11):2825-2828.

50. Ganz T. Anemia of inflammation. N Engl J Med. 2019;381 (12):1148-1157. doi:10.1056/NEJMra1804281

51. Macciò A, Madeddu C, Massa D, et al. Hemoglobin levels correlate with interleukin-6 levels in patients with advanced untreated epithelial ovarian cancer: role of inflammation in cancer-related anemia. Blood. 2005;106(1):362-367. doi:10.1182/blood-2005-01-0160
52. Gilreath JA, Rodgers GM. How I treat cancer-associated anemia. Blood. 2020;136(7):801-813. doi:10.1182/ blood.2019004017

53. Proctor MJ, Morrison DS, Talwar D, et al. An inflammation-based prognostic score (mGPS) predicts cancer survival independent of tumour site: a Glasgow Inflammation Outcome Study. $\mathrm{Br} J$ Cancer. 2011;104(4):726-734. doi:10.1038/sj.bjc. 6606087

54. Crawford J, Cella D, Cleeland CS, et al. Relationship between changes in hemoglobin level and quality of life during chemotherapy in anemic cancer patients receiving epoetin alfa therapy. Cancer. 2002;95(4):888-895. doi:10.1002/cncr.10763

55. Davies KJ, Maguire JJ, Brooks GA, Dallman PR, Packer L. Muscle mitochondrial bioenergetics, oxygen supply, and work capacity during dietary iron deficiency and repletion. $\mathrm{Am}$ J Physiol. 1982;242(6):E418-E427. doi:10.1152/ ajpendo.1982.242.6.E418

56. Poulos TL. Heme enzyme structure and function. Chem Rev. 2014;114(7):3919-3962.

57. Weiss G, Goodnough LT. Anemia of chronic disease. $N$ Engl $J$ Med. 2005;352(10):1011-1023. doi:10.1056/NEJMra041809

58. Carson JL, Grossman BJ, Kleinman S, et al. Red blood cell transfusion: a clinical practice guideline from the AABB. Ann Intern Med. 2012;157(1):49-58. doi: 10.7326/0003-4819-157-1201206190-00429

59. Mercadante S, Ferrara P, Villari P, David F, Giarratano A, Riina S. Effects of red blood transfusion on anemia-related symptoms in patients with cancer. $J$ Palliat Med. 2009;12(1):60-63. doi:10.1089/jpm.2008.0139

60. Callum JL, Waters JH, Shaz BH, Sloan SR, Murphy MF. The AABB recommendations for the choosing wisely campaign of the American Board of Internal Medicine. Transfusion. 2014;54 (9):2344-2352. doi:10.1111/trf.12802

61. Aapro M, Chernov VM, Gladkov OA, et al. Practical recommendations for the treatment of anemia in cancer patients. Malignant Tumors. 2016;4:368-377.

62. Bohlius J, Bohlke K, Castelli R, et al. Management of Cancer-Associated anemia with erythropoiesis-stimulating agents: ASCO/ASH Clinical Practice Guideline Update. $J \quad$ Clin Oncol. 2019;37(15):1336-1351. doi:10.1200/ JCO.18.02142

63. Aapro M, Beguin Y, Bokemeyer C, et al.; ESMO Guidelines Committee. Management of anaemia and iron deficiency in patients with cancer: ESMO clinical practice guidelines. Ann Oncol. 2018;29(Suppl 4):iv96-iv110. doi:10.1093/annonc/ $\operatorname{mdx} 758$

64. Carson JL, Carless PA, Hebert PC. Transfusion thresholds and other strategies for guiding allogeneic red blood cell transfusion. Cochrane Database Syst Rev. 2018;4(4):CD002042.

65. Goodnough LT. Risks of blood transfusion. Anesthesiol Clin North Am. 2005;23(2):241-252. doi:10.1016/j.atc.2004.07.004

66. Khorana AA, Francis CW, Blumberg N, Culakova E, Refaai MA, Lyman GH. Blood transfusions, thrombosis, and mortality in hospitalized patients with cancer. Arch Intern Med. 2008;168(21):2377-2381. doi:10.1001/archinte. 168.21.2377

67. Goubran HA, Elemary M, Radosevich M, Seghatchian J, ElEkiaby M, Burnouf T. Impact of transfusion on cancer growth and outcome. Cancer Growth Metastasis. 2016;9:1-8. doi:10.4137/CGM.S32797

68. De Oliveira GS Jr, Schink JC, Buoy C, et al. The association between allogeneic perioperative blood transfusion on tumour recurrence and survival in patients with advanced ovarian cancer. Transfus Med. 2012;22(2):97-103. doi:10.1111/j.13653148.2011.01122.x 
69. Youssef LA, Spitalnik SL. Transfusion-related immunomodulation: a reappraisal. Curr Opin Hematol. 2017;24(6):551-557. doi:10.1097/MOH.0000000000000376

70. Hedenus M, Adriansson M, San Miguel J, et al.; Darbepoetin Alfa 20000161 Study Group. Efficacy and safety of darbepoetin alfa in anaemic patients with lymphoproliferative malignancies: a randomized, double-blind, placebo-controlled study. $\mathrm{Br}$ $J \quad$ Haematol. 2003;122(3):394-403. doi:10.1046/j.13652141.2003.04448.x

71. Littlewood TJ, Bajetta E, Nortier JW, Vercammen E, Rapoport B; Epoetin Alfa Study Group. Effects of epoetin alfa on hematologic parameters and quality of life in cancer patients receiving nonplatinum chemotherapy: results of a randomized, double-blind, placebo-controlled trial. J Clin Oncol. 2001;19(11):2865-2874. doi:10.1200/JCO.2001.19.11.2865

72. Vansteenkiste J, Pirker R, Massuti B, et al. Double-blind, placebocontrolled, randomized phase III trial of darbepoetin alfa in lung cancer patients receiving chemotherapy. J Natl Cancer Inst. 2002;94(16):1211-1220. doi:10.1093/jnci/94.16.1211

73. Tonia T, Mettler A, Robert N, et al. Erythropoietin or darbepoetin for patients with cancer. Cochrane Database Syst Rev. 2012;12: CD003407. doi:10.1002/14651858.CD003407.pub5

74. Bohlius J, Tonia $\mathrm{T}$, Nüesch $\mathrm{E}$, et al. Effects of erythropoiesis-stimulating agents on fatigue- and anaemia-related symptoms in cancer patients: systematic review and meta-analyses of published and unpublished data. $\mathrm{Br}$ $J$ Cancer. 2014;111(1):33-45. doi:10.1038/bjc.2014.171

75. Aapro M. An update on twenty years of anemia management with erythropoiesis-stimulating agents in nephrology and oncology/ hematology. Oncologist. 2009;14(Suppl 1):1-5. doi:10.1634/ theoncologist.2009-S1-1

76. Bohlius J, Weingart O, Trelle S, Engert A. Cancer-related anemia and recombinant human erythropoietin-an updated overview. Nat Clin Pract Oncol. 2006;3(3):152-164. doi:10.1038/ncponc0451

77. U.S. Food and Drug Administration. Biosimilar and Interchangeable Products; 2017. Available from: https://www. fda.gov/drugs/biosimilars/biosimilar-and-interchangeableproducts. Accessed February 06, 2021.

78. U.S. Food and Drug Administration. Oncologic drugs advisory committee meeting. "Epoetin Hospira", a proposed biosimilar to US-licensed Epogen/Procrit; 2017. Available from: https:/www. fda.gov/media/105760/download. Accessed February 06, 2021.

79. US Food and Drug Administration. FDA approves Retacrit as a biosimilar to Epogen/Procrit. Available from: https://www.fda. gov/drugs/resources-information-approved-drugs/fda-approvesretacrit-biosimilar-epogenprocrit. Accesed June 18, 2021.

80. Smith RE Jr, Aapro MS, Ludwig H, et al. Darbepoetin alpha for the treatment of anemia in patients with active cancer not receiving chemotherapy or radiotherapy: results of a Phase III, multicenter, randomized, double-blind, placebo-controlled study. J Clin Oncol. 2008;26(7):1040-1050. doi:10.1200/JCO.2007.14.2885

81. Gordon D, Nichols G, Ben-Jacob A, Tomita D, Lillie T, Miller C. Treating anemia of cancer with every-4-week darbepoetin alfa: final efficacy and safety results from a Phase II, Randomized, Double-Blind, Placebo-Controlled Study. Oncologist. 2008;13 (6):715-724. doi:10.1634/theoncologist.2007-0241

82. Grant MD, Piper M, Bohlius J, et al. Epoetin and darbepoetin for managing anemia in patients undergoing cancer treatment: comparative effectiveness update [Internet]. Rockville (MD): Agency for Healthcare Research and Quality (US); 2013. Report No.:13EHC077-EF.

83. Tonelli M, Hemmelgarn B, Reiman T, et al. Benefits and harms of erythropoiesis-stimulating agents for anemia related to cancer: a meta-analysis. CMAJ. 2009;180(11):E62-71. doi:10.1503/ cmaj.090470
84. Bohlius J, Schmidlin K, Brillant C, et al. Recombinant human erythropoiesis stimulating agents and mortality in patients with cancer: a meta-analysis of randomized trials. Lancet. 2009;373 (9674):1532-1542. doi:10.1016/S0140-6736(09)60502-X

85. Aapro M, Osterwalder B, Scherhag A, Burger HU. Epoetin-beta treatment in patients with cancer chemotherapy-induced anaemia: the impact of initial haemoglobin and target haemoglobin levels on survival, tumour progression and thromboembolic events. Br J Cancer. 2009;101(12):1961-1971. doi:10.1038/sj. bjc. 6605255

86. Bohlius J, Schmidlin K, Brillant C, et al. Erythropoietin or Darbepoetin for patients with cancer: meta-analysis based on individual patient data. Cochrane Database Syst Rev. 2009;2009 (3):CD007303.

87. Lyman GH, Bohlke K, Khorana AA, et al.; American Society of Clinical Oncology. Venous thromboembolism prophylaxis and treatment in patients with cancer: american society of clinical oncology clinical practice guideline update 2014. J Clin Oncol. 2015;33(6):654-656. doi:10.1200/JCO.2014.59.7351

88. Donnellan E, Khorana AA. Cancer and venous thromboembolic disease: a review. Oncologist. 2017;22(2):199-207. doi:10.1634/ theoncologist.2016-0214

89. Jelkmann W, Bohlius J, Hallek M, Sytkowski AJ. The erythropoietin receptor in normal and cancer tissues. Crit Rev Oncol Hematol. 2008;67(1):39-61.

90. Sinclair AM, Todd MD, Forsythe K, Knox SJ, Elliott S, Begley CG. Expression and function of erythropoietin receptors in tumors: implications for the use of erythropoiesis-stimulating agents in cancer patients. Cancer. 2007;110(3):477-488. doi:10.1002/cncr.22832

91. Glaspy J, Crawford J, Vansteenkiste J, et al. Erythropoiesisstimulating agents in oncology: a study-level meta-analysis of survival and other safety outcomes. Br J Cancer. 2010;102 (2):301-315. doi:10.1038/sj.bjc.6605498

92. Engert A, Josting A, Haverkamp H, et al. Epoetin alfa in patients with advanced-stage Hodgkin's lymphoma: results of the randomized placebo-controlled GHSG HD15EPO trial. J Clin Oncol. 2010;28(13):2239-2245. doi:10.1200/JCO.2009.25.1835

93. Nitz U, Gluz O, Zuna I, et al. West German Study Group. Final results from the prospective phase III WSG-ARA trial: impact of adjuvant darbepoetin alfa on event-free survival in early breast cancer. Ann Oncol. 2014;25(1):75-80. doi:10.1093/annonc/ mdt505

94. Pirker R, Ramlau RA, Schuette W, et al. Safety and efficacy of darbepoetin alpha in previously untreated extensive-stage small-cell lung cancer treated with platinum plus etoposide. J Clin Oncol. 2008;26(14):2342-2349. doi:10.1200/JCO.2007.15.0748

95. McKoy JM, Stonecash RE, Cournoyer D, et al. Epoetinassociated pure red cell aplasia: past, present, and future considerations. Transfusion. 2008;48(8):1754-1762. doi:10.1111/ j.1537-2995.2008.01749.x

96. Bohlius J, Bohlke K, Castelli R, et al. Management of cancer-associated anemia with erythropoiesis-stimulating agents: ASCO/ASH clinical practice guideline update. Blood Adv. 2019;3 (8):1197-1210. doi:10.1182/bloodadvances.2018030387

97. Abdel-Razeq H, Hashem H. Recent update in the pathogenesis and treatment of chemotherapy and cancer induced anemia. Crit Rev Oncol Hematol. 2020;145:102837. doi:10.1016/j. critrevonc. 2019.102837

98. Weiss G, Ganz T, Goodnough LT. Anemia of inflammation. Blood. 2019;133(1):40-50. doi:10.1182/blood-2018-06-856500

99. Toblli JE, Angerosa M. Optimizing iron delivery in the management of anemia: patient considerations and the role of ferric carboxymaltose. Drug Des Dev Ther. 2014;8:2475-2491. doi:10.2147/DDDT.S55499 
100. Baribeault D, Auerbach M. Iron replacement therapy in cancer-related anemia. Am J Health Syst Pharm. 2011;68(10 Suppl 1):S4-S14. doi:10.2146/ajhp110039

101. Mhaskar R, Wao H, Miladinovic B, Kumar A, Djulbegovic B. The role of iron in the management of chemotherapy-induced anemia in cancer patients receiving erythropoiesis stimulating agents. Cochrane Database Syst Rev. 2016;2:CD009624. doi:10.1002/14651858.CD009624.pub2

102. Auerbach M, Silberstein PT, Webb RT, et al. Darbepoetin alfa 300 or $500 \mathrm{mg}$ once every 3 weeks with or without intravenous iron in patients with chemotherapy-induced anemia. Am J Hematol. 2010;85(9):655-663. doi:10.1002/ajh.21779

103. Bastit L, Vandebroek A, Altintas S, et al. Randomized, multicenter, controlled trial comparing the efficacy and safety of darbepoetin alpha administered every 3 weeks with or without intravenous iron in patients with chemotherapy-induced anemia. $J$ Clin Oncol. 2008;26(10):1611-1618. doi:10.1200/ JCO.2006.10.4620

104. Gafter-Gvili A, Rozen-Zvi B, Vidal L, et al. Intravenous iron supplementation for the treatment of chemotherapy anaemia: systematic review and meta-analysis of randomized controlled studies. Acta Oncol. 2013;52(1):18-29. doi:10.3109/ 0284186X.2012.702921

105. Steensma DP, Sloan JA, Dakhil SR, et al. Phase III, randomized study of the effects of parenteral iron, oral iron, or no iron supplementation on the erythropoietic response to darbepoetin alfa for patients with chemotherapy-associated anemia. $J$ Clin Oncol. 2011;29(1):97-105. doi:10.1200/ JCO.2010.30.3644

106. Jang JH, Kim Y, Park S, et al. Efficacy of intravenous iron treatment for chemotherapy-induced anemia: a prospective phase II pilot clinical trial in South Korea. Plos Med. 2020;17 (6):e1003091. doi:10.1371/journal.pmed.1003091

107. Steensma DP, Sasu BJ, Sloan JA, Tomita DK, Loprinzi CL. Serum hepcidin levels predict response to intravenous iron and darbepoetin in chemotherapy-associated anemia. Blood. 2015;125 (23):3669-3671. doi:10.1182/blood-2015-03-636407

108. Gozzelino R, Arosio P. Iron homeostasis in health and disease. Int J Mol Sci. 2016;17(1):130. doi:10.3390/ijms 17010130

109. González-Chávez SA, Arévalo-Gallegos S, Rascón-Cruz Q. Lactoferrin: structure, function and applications. Int $J$ Antimicrob Agents. 2009;33(4):301.e1-8. doi:10.1016/j. ijantimicag.2008.07.020

110. Macciò A, Madeddu C, Gramignano G, Mulas C, Sanna E, Mantovani G. Efficacy and safety of oral lactoferrin supplementation in combination with rHuEPO-b for the treatment of anemia in advanced cancer patients undergoing chemotherapy: open-label, randomized controlled study. Oncologist. 2010;15 (8):894-902. doi:10.1634/theoncologist.2010-0020

111. Cooke KS, Hinkle B, Salimi-Moosavi H, et al. A fully human anti-hepcidin antibody modulates iron metabolism in both mice and nonhuman primates. Blood. 2013;122(17):3054-3061. doi:10.1182/blood-2013-06-505792

112. Vadhan-Raj S, Abonour R, Goldman JW, et al. A first-in-human Phase 1 study of a hepcidin monoclonal antibody, LY2787106, in cancer-associated anemia. J Hematol Oncol. 2017;10(1):73. doi:10.1186/s13045-017-0427-x

113. Park EJ, Choi J, Lee KC, Na DH. Emerging PEGylated non-biologic drugs. Expert Opin Emerg Drugs. 2019;24 (2):107-119. doi:10.1080/14728214.2019.1604684

114. Georgiev P, Lazarolu M, Ocroteala L, et al. The anti-hepcidin Spiegelmer Lexapeptid Pegol (NOX-H94) as treatment of anemia of chronic disease in patients with multiple myeloma, low grade lymphoma and CLL: a phase II pilot study. AACR Meeting; 2014:Abstract 3847.
115. Haase VH. Therapeutic targeting of the HIF oxygen-sensing pathway: lessons learned from clinical studies. Exp Cell Res. 2017;356(2):160-165. doi:10.1016/j.yexcr.2017.05.004

116. Forristal CE, Levesque JP. Targeting the hypoxia-sensing pathway in clinical hematology. Stem Cell Transl Med. 2014;3 (2):135-140. doi:10.5966/sctm.2013-0134

117. Wan J, Chai H, Yu Z, et al. HIF-1 $\alpha$ effects on angiogenic potential in human small cell lung carcinoma. J Exp Clin Cancer Res. 2011;30(1):77. doi:10.1186/1756-9966-30-77

118. Seeley TW, Sternlicht MD, Klaus SJ, Neff TB, Liu DY. Induction of erythropoiesis by hypoxia-inducible factor prolyl hydroxylase inhibitors without promotion of tumor initiation, progression, or metastasis in a VEGF-sensitive model of spontaneous breast cancer. Hypoxia (Auckl). 2017;5:1-9. doi:10.2147/HP.S130526

119. Bayliss TJ, Smith JT, Schuster M, Dragnev KH, Rigas JR. A humanized anti-IL-6 antibody (ALD518) in non-small cell lung cancer. Expert Opin Biol Ther. 2011;11(12):1663-1668. doi:10.1517/14712598.2011.627850

120. Coward J, Kulbe H, Chakravarty $P$, et al. Interleukin-6 as a therapeutic target in human ovarian cancer. Clin Cancer Res. 2011;17(18):6083-6096. doi:10.1158/1078-0432.CCR-11-0945

121. Pauklin S, Vallier L. Activin/nodal signaling in stem cells. Development. 2015;142(4):607-619. doi:10.1242/dev.091769

122. Miller KL, Carlino JA, Ogawa Y, Avis PD, Carroll KG. Alterations in erythropoiesis in TGF-b 1-treated mice. Exp Hematol. 1992;20(8):951-956.

123. Kang YJ, Shin JW, Yoon JH, et al. Inhibition of erythropoiesis by Smad6 in human cord blood hematopoietic stem cells. Biochem Biophys Res Commun. 2011;423(4):750-756. doi:10.1016/j. bbrc.2012.06.031

124. Brancaleoni V, Nava I, Delbini P, Duca L, Motta I. Activin receptor-ligand trap for the treatment of $\beta$-thalassemia: a serendipitous discovery. Mediterr $J$ Hematol Infect Dis. 2020;12(1):e2020075. doi:10.4084/mjhid.2020.075

125. Testa U, Castelli G, Elvira P. Experimental and investigational therapies for chemotherapy-induced anemia. Expert Opin Investig Drugs. 2015;24(11):1433-1445. doi:10.1517/ 13543784.2015.1085505

126. Patel B, Moosavi L. Luspatercept. In: StatPearls [Internet]. Treasure Island (FL): StatPearls Publishing LLC; July 10, 2020.

127. Fenaux P, Kiladjian JJ, Platzbecker U. Luspatercept for the treatment of anemia in myelodysplastic syndromes and primary myelofibrosis. Blood. 2019;133(8):790-794. doi:10.1182/blood2018-11-876888

128. Fenaux P, Platzbecker U, Mufti GJ, et al. Luspatercept in patients with lower-risk myelodysplastic syndromes. $N$ Engl $\mathrm{J} \mathrm{Med}$. 2020;382(2):140-151. doi:10.1056/NEJMoa1908892

129. Kubasch AS, Fenaux P, Platzbecker U. Development of luspatercept to treat ineffective erythropoiesis. Blood Adv. 2021;5 (5):1565-1575. doi:10.1182/bloodadvances.2020002177

130. Feld J, Navada SC, Silverman LR. Myelo-deception: luspatercept \& TGF-Beta ligand traps in myeloid diseases \& anemia. Leuk Res. 2020;97:106430. doi:10.1016/j.leukres.2020.106430

131. Raftopoulos H, Laadem A, Hesketh PJ, et al. Sotatercept (ACE-011) for the treatment of chemotherapy-induced anemia in patients with metastatic breast cancer or advanced or metastatic solid tumors treated with platinum-based chemotherapeutic regimens: results from two Phase 2 studies. Support Care Cancer. 2016;24(4):1517-1525. doi:10.1007/s00520-015-2929-9

132. Layer G, Reichelt J, Jahn D, Heinz DW. Structure and function of enzymes in heme biosynthesis. Protein Sci. 2010;19 (6):1137-1161. doi:10.1002/pro.405

133. Madeddu C, Mantovani G, Gramignano G, Astara G, Macciò A. Muscle wasting as main evidence of energy impairment in cancer cachexia: future therapeutic approaches. Future Oncol. 2015;11 (19):2697-2710. doi:10.2217/fon.15.195 
134. Friesen DE, Baracos VE, Tuszynski JA. Modeling the energetic cost of cancer as a result of altered energy metabolism: implications for cachexia. Theor Biol Med Model. 2015;12:17. doi:10.1186/s12976-015-0015-0

135. Santino A, Scarano A, De Santis S, De Benedictis M, Giovinazzo G, Chieppa M. Gut microbiota modulation and anti-inflammatory properties of dietary polyphenols in IBD: new and consolidated perspectives. Curr Pharm Des. 2017;23 (16):2344-2351. doi:10.2174/1381612823666170207145420

136. Rahman I, Biswas SK, Kirkham PA. Regulation of inflammation and redox signaling by dietary polyphenols. Biochem Pharmacol. 2006;72(11):1439-1452. doi:10.1016/j.bcp.2006.07.004

137. Yahfoufi N, Alsadi N, Jambi M, Matar C. The Immunomodulatory and anti-inflammatory role of polyphenols. Nutrients. 2018;10(11):1618. doi:10.3390/nu10111618

138. Fatih N, Camberlein E, Island ML, et al. Natural and synthetic STAT3 inhibitors reduce hepcidin expression in differentiated mouse hepatocytes expressing the active phosphorylated STAT3 form. J Mol Med (Berl). 2010;88(5):477-486. doi:10.1007/ s00109-009-0588-3

139. Lainé F, Laviolle B, Bardou-Jacquet E, et al. Curcuma decreases serum hepcidin levels in healthy volunteers: a placebo-controlled, randomized, double-blind, cross-over study. Fundam Clin Pharm. 2017;31(5):567-573. doi:10.1111/fcp.12288

140. Jiao Y, Wilkinson J, Di X, et al. Curcumin, a cancer chemopreventive and chemotherapeutic agent, is a biologically active iron chelator. Blood. 2009;113(2):462-469. doi:10.1182/blood-2008-05155952

141. Mohammadi E, Tamaddoni A, Qujeq D, et al. An investigation of the effects of curcumin on iron overload, hepcidin level, and liver function in $\beta$-thalassemia major patients: a double-blind randomized controlled clinical trial. Phytother Res. 2018;32 (9):1828-1835. doi:10.1002/ptr.6118

142. Macciò A, Gramignano G, Madeddu C. A multitargeted treatment approach for anemia and cachexia in metastatic castration-resistant prostate cancer. J Pain Symptom Manage. 2015;50(2):e1-e4. doi:10.1016/j.jpainsymman.2015.04.014

143. Macciò A, Gramignano G, Madeddu C. Surprising results of a supportive integrated therapy in myelofibrosis. Nutrition. 2015;31(1):239-243. doi:10.1016/j.nut.2014.07.016

144. Endo K, Tsuji A, Kondo S, Wakisaka N, Murono S, Yoshizaki T. Carnitine is associated with fatigue following chemoradiotherapy for head and neck cancer. Acta Otolaryngol. 2015;135 (8):846-852. doi:10.3109/00016489.2015.1030769

145. Hockenberry MJ, Hooke MC, Gregurich M, McCarthy K. Carnitine plasma levels and fatigue in children/adolescents receiving cisplatin, ifosfamide, or doxorubicin. J Pediatr Hematol Oncol. 2009;31(9):664-669. doi:10.1097/MPH.0b013e3181b259a7

146. Cruciani RA, Dvorkin E, Homel P, et al. L-carnitine supplementation in patients with advanced cancer and carnitine deficiency: a double-blind, placebo-controlled study. J Pain Symptom Manage. 2009;37(4):622-631. doi:10.1016/j.jpainsymman.2008.03.021

147. Morris MS, Jacques PF, Rosenberg IH, Selhub J. Folate and vitamin B-12 status in relation to anemia, macrocytosis, and cognitive impairment in older Americans in the age of folic acid fortification. Am J Clin Nutr. 2007;85(1):193-200. doi:10.1093/ ajcn/85.1.193

148. Lonsdale D. A review of the biochemistry, metabolism and clinical benefits of thiamin(e) and its derivatives. Evid Based Complement Alternat Med. 2006;3(1):49-59. doi:10.1093/ecam/ nek009
149. Parra M, Stahl S, Hellmann H. Vitamin $B_{6}$ and its role in cell metabolism and physiology. Cells. 2018;7(7):84. doi:10.3390/ cells 7070084

150. Smith EM, Tangpricha V. Vitamin D and anemia: insights into an emerging association. Curr Opin Endocrinol Diabetes Obes. 2015;22(6):432-438. doi:10.1097/MED.0000000000000199

151. Zughaier SM, Alvarez JA, Sloan JH, Konrad RJ, Tangpricha V. The role of vitamin D in regulating the iron-hepcidin-ferroportin axis in monocytes. J Clin Transl Endocrinol. 2014;1(1):19-25. doi:10.1016/j.jcte.2014.01.003

152. Perlstein TS, Pande R, Berliner N, Vanasse GJ. Prevalence of 25-hydroxyvitamin D deficiency in subgroups of elderly persons with anemia: association with anemia of inflammation. Blood. 2011;117(10):2800-2806. doi:10.1182/blood-2010-09-309708

153. Icardi A, Paoletti E, De Nicola L, Mazzaferro S, Russo R, Cozzolino M. Renal anaemia and EPO hyporesponsiveness associated with vitamin D deficiency: the potential role of inflammation. Nephrol Dial Transplant. 2013;28(7):1672-1679. doi:10.1093/ndt/gft021

154. Smith EM, Alvarez JA, Kearns MD, et al. High-dose vitamin D3 reduces circulating hepcidin concentrations: a pilot, randomized, double-blind, placebo-controlled trial in healthy adults. Clin Nutr. 2017;36(4):980-985. doi:10.1016/j.clnu.2016.06.015

155. Moran-Lev H, Galai T, Yerushalmy-Feler A, et al. Vitamin $\mathrm{D}$ decreases hepcidin and inflammatory markers in newly diagnosed inflammatory bowel disease paediatric patients: a Prospective Study. J Crohn's Colitis. 2019;13(10):1287-1291. doi:10.1093/ecco-jcc/jjz056

156. Pasini E, Corsetti G, Romano C, et al. Management of anaemia of chronic disease: beyond iron-only supplementation. Nutrients. 2021;13(1):237. doi:10.3390/nu13010237

157. Hallberg L, Brune M, Rossander L. Iron absorption in man: ascorbic acid and dose-dependent inhibition by phytate. Am $J$ Clin Nutr. 1989;49(1):140-144. doi:10.1093/ajcn/49.1.140

158. Lane DJ, Richardson DR. The active role of vitamin C in mammalian iron metabolism: much more than just enhanced iron absorption! Free Radic Biol Med. 2014;75:69-83. doi:10.1016/j. freeradbiomed.2014.07.007

159. Chiu PF, Ko SY, Chang CC. Vitamin C affects the expression of hepcidin and erythropoietin receptor in HepG2 cells. J Ren Nutr. 2012;22(3):373-376. doi:10.1053/j.jrn.2011.09.007

160. Attallah N, Osman-Malik Y, Frinak S, Besarab A. Effect of intravenous ascorbic acid in hemodialysis patients with EPO-hyporesponsive anemia and hyperferritinemia. $\mathrm{Am}$ J Kidney Dis. 2006;47(4):644-654. doi:10.1053/j. ajkd.2005.12.025

161. Barni S, Gascòn P, Petrelli F, et al. Position paper on management of iron deficiency in adult cancer patients. Expert Rev Hematol. 2017;10(8):685-695. doi:10.1080/17474086.2017.1343140

162. Steinmetz T, Tschechne B, Harlin O, et al. Clinical experience with ferric carboxymaltose in the treatment of cancer- and chemotherapy-associated anaemia. Ann Oncol. 2013;24 (2):475-482. doi:10.1093/annonc/mds338

163. Toledano A, Luporsi E, Morere JF, et al. Clinical use of ferric carboxymaltose in patients with solid tumours or haematological malignancies in France. Support Care Cancer. 2016;24(1):67-75. doi:10.1007/s00520-015-2728-3 


\section{Publish your work in this journal}

The Journal of Experimental Pharmacology is an international, peerreviewed, open access journal publishing original research, reports, reviews and commentaries on all areas of laboratory and experimental pharmacology. The manuscript management system is completely online and includes a very quick and fair peer-review system. Visit http://www.dovepress.com/testimonials.php to read real quotes from published authors.

Submit your manuscript here: https://www.dovepress.com/journal-of-experimental-pharmacology-journal 